\title{
Novel WS2-based nanofluids for concentrating solar power: performance characterization and molecular-level insights
}

Article

Accepted Version

Martínez-Merino, P., Midgley, S. D., Martín, E. I., Estellí, P., Alcántara, R., Sánchez-Coronilla, A., Grau-Crespo, R. and Navas, J. (2020) Novel WS2-based nanofluids for concentrating solar power: performance characterization and molecular-level insights. ACS Applied Materials \& Interfaces, 12 (5). pp. 5793-5804. ISSN 1944-8244 doi: https://doi.org/10.1021/acsami.9b18868 Available at https://centaur.reading.ac.uk/88909/

It is advisable to refer to the publisher's version if you intend to cite from the work. See Guidance on citing.

To link to this article DOI: http://dx.doi.org/10.1021/acsami.9b18868

Publisher: ACS Publications

All outputs in CentAUR are protected by Intellectual Property Rights law, including copyright law. Copyright and IPR is retained by the creators or other copyright holders. Terms and conditions for use of this material are defined in the End User Agreement. 


\section{www.reading.ac.uk/centaur}

\section{CentAUR}

Central Archive at the University of Reading

Reading's research outputs online 


\title{
Novel $\mathrm{WS}_{2}$-based nanofluids for concentrating solar power: performance characterization and molecular-level insights
}

\author{
Paloma Martínez-Merino, ${ }^{1}$ Scott D. Midgley, ${ }^{2}$ Elisa I. Martín, ${ }^{3}$ Patrice Estellé, ${ }^{4}$ Rodrigo \\ Alcántara, ${ }_{1}^{1}$ Antonio Sánchez-Coronilla, ${ }^{3}$ Ricardo Grau-Crespo, ${ }^{2}$ Javier Navas ${ }^{*}, 1$ \\ ${ }^{1}$ Departamento de Química Física, Facultad de Ciencias, Universidad de Cádiz, E-11510 Puerto Real (Cádiz), \\ Spain. \\ ${ }^{2}$ Department of Chemistry, University of Reading, Whiteknights, Reading RG6 6AD, United Kingdom. \\ ${ }^{3}$ Universidad de Sevilla, Departamento de Ingeniería Química-Facultad de Química; Departamento de Química \\ Física-Facultad de Farmacia, E-41012 Sevilla, Spain. \\ ${ }^{4}$ Univ Rennes, LGCGM, EA3913, F-35000 Rennes, France.
}

Corresponding Author:

*Javier Navas (javier.navas@uca.es).

Keywords: $\mathrm{WS}_{2}$ nanosheets; Nanofluids; Dissociative adsorption; Ab-initio Molecular Dynamics; Surface chemistry; Concentrating Solar Power. 


\begin{abstract}
Nano-colloidal suspensions of nanomaterials in a fluid, nanofluids, are appealing because of their interesting properties related to heat transfer processes. Whilst nanomaterials based on transition metal chalcogenides (TMCs) have been widely studied in catalysis, sensing, and energy storage applications, there are few studies of nanofluids based on TMCs for heat transfer applications. In this study, the preparation and analysis of nanofluids based on 2D$\mathrm{WS}_{2}$ in a typical heat transfer fluid (HTF) used in concentrating solar power (CSP) plants is reported. Nanofluids prepared using an exfoliation process exhibited well-defined nanosheets and were highly stable. The nanofluids were characterized in terms of properties related to their application in CSP. The presence of $\mathrm{WS}_{2}$ nanosheets did not modify significantly the surface tension, the viscosity, or the isobaric specific heat, but the thermal conductivity was improved by up to $30 \%$. The $U_{\mathrm{r}}$ factor, which characterizes the thermal efficiency of the fluid in the solar collector, shows an enhancement of up to $22 \%$ in the nanofluid, demonstrating great promise for CSP applications. The Reynolds number and friction factor of the fluid were not significantly modified by the addition of the nanomaterial to the HTF, which is also positive for practical applications in CSP plants. Ab initio molecular dynamics simulations of the nanoparticle/fluid interface showed an irreversible dissociative adsorption of diphenyl oxide molecules on the $\mathrm{WS}_{2}$ edge, with very low kinetic barrier. The resulting 'decoration' of the $\mathrm{WS}_{2}$ edge dramatically affects the nature of the interface interactions and is therefore expected to affect significantly the rheological and transport properties of the nanofluids.
\end{abstract}




\section{Introduction}

Nano-colloids or nanofluids are colloidal suspensions of nanomaterials in a fluid. The addition of nanomaterials can modify properties such as the thermal conductivity, isobaric specific heat or heat transfer coefficient of the fluid. Therefore, nanofluids constitute an emerging technology for the improvement of heat transfer fluids (HTFs), ${ }^{1-4}$ and they are considered as promising alternatives to conventional HTFs in several applications, such as electronic cooling, ${ }^{5}$ nuclear reactors,${ }^{6}$ thermal energy storage ${ }^{7}$ and biomedical applications. ${ }^{8}$ Nowadays, one of their most interesting applications is in solar energy systems. The presence of nanoparticles can lead to an increase in the absorption of incident solar radiation, which improves the global efficiency of the collectors. ${ }^{9-10}$ Nanofluids could enhance the features of the HTFs used in solar energy applications, more specifically in concentrating solar power (CSP) plants based on parabolic trough collectors. Here, the typical HTF used is the eutectic mixture of diphenyl oxide and biphenyl. ${ }^{11}$ Improvements in the thermal properties of the HTFs can lead to an enhancement of the global efficiency of CSP plants. ${ }^{12-14}$ Since Choi first reported interesting enhancements of the thermal properties of fluids thanks to the incorporation of nanoparticles, ${ }^{15}$ many studies have analyzed this effect and reported significant improvements in thermal conductivity. For example, Chen et al showed an improvement of about $20 \%$ for nanofluids based on carbon nanotubes, ${ }^{16}$ while Xuan et al.

found enhancements of about $60 \%$ for nanofluids obtained using $\mathrm{Cu}$ nanoparticles in water. ${ }^{17}$ However, an important issue surrounding nanofluids is that they should be stable, because nanofluids showing high stability have improved thermal properties over the time. Twodimensional nanomaterial may therefore be an interesting alternative to metallic or metal oxide nanoparticles because they present good physical stability, which can lead to a decrease 
in agglomeration and sedimentation processes when they are included in colloidal suspensions, mainly thanks to their higher surface area.

The present work shows the preparation of nanofluids based on $2 \mathrm{D}-\mathrm{WS}_{2}$ and the typical synthetic oil used in CSP plants based on parabolic trough collector technology. ${ }^{11}$ The 2D nanostructures were prepared in situ in the fluid using a liquid phase exfoliation method. The nanofluids were characterized in terms of their stability and properties related to their efficiency in heat transfer processes, such as rheological and thermal properties. To understand the behavior of the nanofluids at the molecular level, theoretical calculations were performed based on molecular dynamics and ab-initio molecular dynamics.

\section{Materials and methods}

\subsection{Preparation of nanofluids}

A nanofluid consists of three components: the fluid, the nanomaterial and the stabilizing agent or surfactant. For preparing stable nanofluids, the components are chosen according to the following considerations. The thermodynamic requirements for obtaining a stable colloidal suspension are reached when the tension at the solid-liquid interface, $\gamma_{\mathrm{SL}}$, is minimized. Fowkes ${ }^{18}$ and Owens-Wendt ${ }^{19}$ defined $\gamma_{\text {SL }}$ as:

$$
\gamma_{\mathrm{SL}}=\left(\frac{\gamma_{\mathrm{S}}^{\mathrm{p}}}{\gamma_{\mathrm{S}}^{\mathrm{d}}}+1\right) \gamma_{\mathrm{S}}^{\mathrm{d}}+\left(\frac{\gamma_{\mathrm{L}}^{\mathrm{p}}}{\gamma_{\mathrm{L}}^{\mathrm{d}}}+1\right) \gamma_{\mathrm{L}}^{\mathrm{d}}-2\left(\sqrt{\frac{\gamma_{\mathrm{S}}^{\mathrm{p}} \gamma_{\mathrm{L}}^{\mathrm{p}}}{\gamma_{\mathrm{S}}^{\mathrm{d}} \gamma_{\mathrm{L}}^{\mathrm{d}}}+1}\right) \sqrt{\gamma_{\mathrm{S}}^{\mathrm{d}} \gamma_{\mathrm{L}}^{\mathrm{d}}}
$$

where S and L mean solid and liquid, respectively, and $\mathrm{p}$ and $\mathrm{d}$ denote the polar and dispersive components of the surface tension. Therefore, to minimize the tension at the solid-liquid 
interface the magnitudes of the $\gamma_{\mathrm{S}}^{\mathrm{p}} / \gamma_{\mathrm{S}}^{\mathrm{d}}$ and $\gamma_{\mathrm{L}}^{\mathrm{p}} / \gamma_{\mathrm{L}}^{\mathrm{d}}$ ratios should be similar, as should the values of $\gamma_{S}^{d}$ and $\gamma_{L}^{d}$. The values of the polar and dispersive components were obtained using the WORK formula (Wendt, Owens, Rabel and Kaeble) ${ }^{20}$ following the procedure described in the literature ${ }^{21}$ in which surface tension and contact angle are measured. Details of this calculation are shown in the Supporting Information. In this work, the fluid used was the eutectic mixture of diphenyl oxide $\left(\mathrm{C}_{12} \mathrm{H}_{10} \mathrm{O}, 73.5 \%\right)$ and biphenyl $\left(\mathrm{C}_{12} \mathrm{H}_{10}, 26.5 \%\right)$, supplied by The Dow Company@. The nanomaterial used was $\mathrm{WS}_{2}$ (nanopowder, average size: 90 nm, purity > 99\%, Sigma-Aldrich()) and the surfactant was cetyltrimethylammonium bromide (CTAB, purity > 99\%, Sigma-Aldrich $\odot)$. The amount of CTAB was chosen to obtain $\gamma_{\mathrm{S}}^{\mathrm{p}} / \gamma_{\mathrm{S}}^{\mathrm{d}} \approx \gamma_{\mathrm{L}}^{\mathrm{p}} / \gamma_{\mathrm{L}}^{\mathrm{d}}$. The ratio of the polar and dispersive component for bulk $\mathrm{WS}_{2}$ is $0.52 .{ }^{22}$ Several base fluids using different concentrations of CTAB were tested to calculate the ratio between the polar and dispersive components. Table 1 shows the CTAB concentration tested, the values of the surface tension components, and the ratios between them obtained in the experiments. The intermediate concentration tested has the best fit to the ratio of the surface tension components of the base fluid with that of the bulk $\mathrm{WS}_{2}$. After defining the base fluid, a liquid phase exfoliation (LPE) method was used to prepare nanofluids based on $\mathrm{WS}_{2}$ nanosheets. When an LPE method is developed using the appropriate base fluid, the 3D material is exfoliated and 2D nanostructures are obtained. The procedure followed here has been described previously, ${ }^{21}$ and can be summarized as: (i) 3.75 $\mathrm{mg}$ of $3 \mathrm{D} \mathrm{WS} \mathrm{W}_{2}$ and $5 \mathrm{~mL}$ of the base fluid were added to four vials; (ii) these were sonicated for $8 \mathrm{~h}$ at $28-32^{\circ} \mathrm{C}$ using an Elma@ Transsonic Tl-H-5 sonication bath $(80 \mathrm{kHz}, 150 \mathrm{~W})$; (iii) the colloidal suspension was centrifuged twice. The supernatant obtained after the second centrifugation was the nanofluid. The present study considered four nanofluids, which were 
prepared following the procedure described above, under the conditions shown in Table 2. Not all combinations of surfactant concentrations and sonification times are considered because conditions were being optimized after each preparation/characterization cycle.

Table 1. Values of the surface tension and their components, and the ratio between them for the base fluid prepared using different concentrations of CTAB.

\begin{tabular}{ccccc}
\hline $\begin{array}{c}\mathrm{CTAB} / \\
\% \text { wt. }\end{array}$ & $\begin{array}{c}\boldsymbol{\gamma}_{\mathbf{L}} / \\
\mathrm{mN} \mathrm{m}^{-1}\end{array}$ & $\begin{array}{c}\boldsymbol{\gamma}_{\mathbf{L}}^{\mathbf{p}} / \\
\mathrm{mN} \mathrm{m}^{-1}\end{array}$ & $\begin{array}{c}\boldsymbol{\gamma}_{\mathbf{L}}^{\mathbf{d}} / \\
\mathrm{mN} \mathrm{m}^{-1}\end{array}$ & $\boldsymbol{\gamma}_{\mathbf{L}}^{\mathbf{p}} / \boldsymbol{\gamma}_{\mathbf{L}}^{\mathbf{d}}$ \\
\hline $\mathbf{0 . 0 0 9}$ & 35.96 & 13.80 & 22.16 & 0.62 \\
$\mathbf{0 . 0 1 1}$ & 35.61 & 12.62 & 22.99 & 0.55 \\
$\mathbf{0 . 0 1 4}$ & 36.26 & 11.15 & 25.11 & 0.44 \\
\hline
\end{tabular}

Table 2. Preparation conditions for the nanofluids analyzed in this study.

\begin{tabular}{ccc}
\hline Nanofluid & $\begin{array}{c}\text { CTAB } \\
\text { / wt.\% }\end{array}$ & $\begin{array}{c}\text { Sonication } \\
\text { time / h }\end{array}$ \\
\hline$\# \mathbf{1}$ & 0.009 & 4 \\
$\# \mathbf{2}$ & 0.014 & 4 \\
$\# \mathbf{3}$ & 0.009 & 8 \\
$\# \mathbf{4}$ & 0.011 & 8 \\
\hline
\end{tabular}

\subsection{Characterization of nanomaterial and nanofluids}

First, transmission electron microscopy (TEM) was used to analyze the shape and size of the nanostructure obtained from the LPE process. The TEM images were recorded using a JEM2100F microscope supplied by Jeol@. X-ray diffraction (XRD) and X-ray photoelectron spectroscopy (XPS) techniques were also used to test whether the $\mathrm{WS}_{2}$ underwent significant changes during the exfoliation process. A Bruker® D8 Advance A25 diffractometer emitting $\mathrm{Cu}-\mathrm{K} \alpha$ radiation $(1.540 \AA$ ) and a Lynxeye detector were used. The measurement range was from $3^{\circ}$ to $75^{\circ}$ in the $2 \theta$ range, with an accuracy of $0.020^{\circ}$. The measurement conditions were $40.0 \mathrm{kV}$ and $40.0 \mathrm{~mA}$. Furthermore, XPS spectra were recorded using a Kratos Axis 
UltraDLD spectrometer with monochromatized $\mathrm{Al} \mathrm{K \alpha}$ radiation $(1486.6 \mathrm{eV})$, a $20 \mathrm{eV}$ pass energy and given with an accuracy of $0.1 \mathrm{eV}$.

Stability is a key property of nanofluids because it can have a significant effect on the observed thermal properties. Stability was assessed using UV-Vis spectroscopy to analyze the sedimentation process, by evaluating the extinction coefficient and particle size measurements. UV-Vis spectra were recorded using a system consisting of a DH-2000-BAL halogen lamp and a USB2000+ spectrometer, both supplied by Ocean Optics®. Spectra were recorded between 300 and $900 \mathrm{~nm}$ and the extinction coefficient was extracted at $\lambda=629 \mathrm{~nm}$ to analyze the evolution of nanomaterial in suspension in each nanofluid. Particle size measurements were also performed using the dynamic light scattering (DLS) technique by means of a Zetasizer Nano ZS system supplied by Malvern Instruments Ltd®. The extinction coefficient and particle size values were obtained every day in triplicate.

Several measurements were performed to analyze whether the nanofluids prepared could replace the typical HTF used in CSP plants: density, surface tension, dynamic viscosity, isobaric specific heat and thermal conductivity. The fluid used in this study, which is the typical HTF used in CSP plants, was also characterized for comparison purposes.

The density $(\rho)$ values were obtained using temperature-controlled pycnometry. Five values were registered to obtain statistical values. A KRÜSS GmBH DSA-30 Drop Shape Analyzer (Hamburg, Germany) was used to measure the surface tension of samples from the pendant drop technique. The comprehensive experimental procedure followed has been described previously ${ }^{23}$ Surface tension values are determined from the drop shape analysis using the Young-Laplace equation. In this configuration, uncertainty was reported to be less than $0.1 \%$ at ambient condition with calibration gauges and less than $1.08 \%$ for distilled water in the 
temperature range $10-60^{\circ} \mathrm{C} .^{23}$ A Malvern Kinexus Pro stress-controlled rheometer (Malvern Instruments Ltd@, United Kingdom) equipped with cone and plate geometry (60 $\mathrm{mm}$ in diameter and $1^{\circ}$ in angle) is used for rheological evaluation of samples. Temperature was controlled by using a Peltier control system with a precision of $\pm 0.1 \mathrm{~K}$. Measurements were performed applying logarithmic shear stress ramp under steady-state condition once the sample is equilibrated at the required temperature. The uncertainty for viscosity measurement was evaluated to be lower than $4 \%$ in the literature. ${ }^{24}$ Isobaric specific heat $\left(C_{\mathrm{P}}\right)$ was measured using the temperature modulated differential scanning calorimetry (TM-DSC) technique, using a DSC 214 Polyma supplied by Netszch ${ }^{\circledR}$. The program performed to measure the isobaric specific heat has been previously described in the literature. ${ }^{21}$

Thermal conductivity is one of the most important properties of nanofluids prepared for use as a heat transfer fluid. In this study, thermal conductivity $(k)$ was obtained from thermal diffusivity $(D)$ values according to the ASTM E1461-01 standard, which supplies the relationship between both properties as $k(T)=D(T) \cdot C_{\mathrm{P}}(T) \cdot \rho(T)$, where all variables have been defined previously. Thermal diffusivity was measured using the light flash technique using an LFA467 Hyperflash equipment supplied by Netszch®.

\subsection{Computational framework}

In order to get insights into the behavior of the system from a molecular level viewpoint, classical and ab-initio molecular dynamics simulations were performed.

The Transferable Potentials for Phase Equilibria (TraPPE) force field was used for classical molecular dynamics calculations. A cluster of 75 atoms was used for describing the $\mathrm{WS}_{2}$ particle, cut from a unit cell with space group $\mathrm{P}_{3} / \mathrm{mmc}^{25}$ The non-bonded interactions were 
described by using Lennard-Jones and Coulomb potentials, with parameters from the literature. ${ }^{26-27}$ More details about these calculations are shown in the Supporting Information. The DLPOLY code was used to carry out molecular dynamics simulations using periodic boundary conditions. ${ }^{28}$ The canonical ensemble (NVT) was employed, with a Nose-Hoover thermostat at $300 \mathrm{~K}$. The Ewald sum methodology was applied to account for electrostatic interactions. The simulation time was $1 \mathrm{~ns}$, with a time step of $0.5 \mathrm{fs}$. More details of these calculations are shown in the Supporting Information.

For the ab initio molecular dynamics (AIMD) simulations, periodic slab models were used to represent the interaction between prominent $\mathrm{WS}_{2}$ surfaces with the organic solvent (the surfactant was not included). $\mathrm{WS}_{2}$ was cleaved along the (0001) (basal) and the (10-10) (edge) termination planes to create basal-plane and edge-plane slab models. Basal-plane slabs consisted of 6 atomic layers (two $\mathrm{WS}_{2}$ layers) in the direction perpendicular to the surface, whereas edge-plane slabs had a depth of 8 atomic layers. The region between slabs was filled with the same fluid used in the experiments, i.e. diphenyl oxide and biphenyl, in a 3:1 ratio, quite similar to the experimental one. Interface models for both surfaces consisted of 1744 atoms.

The AIMD simulations were performed using the CP2K software package. ${ }^{29}$ All electronic minimizations were carried out using density functional theory (DFT) with the Quickstep implementation $^{30}$ where the orbital transformation method ${ }^{31}$ was employed. DFT calculations used the generalized gradient approximation in the form of the revised PerdewBurke-Ernzerhof (revPBE) exchange-correlation functional. ${ }^{32}$ For a correct representation of dispersion interactions, Grimme's D3 corrections ${ }^{33}$ were applied to all calculations. The single-zeta, molecule-optimized, short-ranged basis sets ${ }^{34}$ (SZV-MOLOPT-SR-GTH) were used with the Goedecker-Teter-Hutter (GTH) pseudopotentials, ${ }^{35}$ to represent atomic cores. 
The simulations were performed within the NVT canonical ensemble (both at $300 \mathrm{~K}$ and 653 K) using the Nose-Hoover thermostat chain ${ }^{36}$ with a time constant of 13 fs. A time step of 1 fs was used, and each simulation ran 9,000 AIMD steps, giving a total simulation time of 9 ps.

Energy barriers to dissociative adsorption were calculated using the nudged-elastic-band (NEB) method as implemented within the Vienna Ab Initio Simulation Package (VASP). ${ }^{37-}$

${ }^{38}$ VASP calculations were performed with the Perdew-Burke-Ernzerhof (PBE) functional, ${ }^{39}$ with Grimme's corrections, and with a planewave energy cutoff of $400 \mathrm{eV}$. The projector augmented wave (PAW) method ${ }^{40-41}$ was used to represent the interaction of electrons with atomic cores, which consisted of levels up to $1 \mathrm{~s}$ for $\mathrm{C}$ and $\mathrm{O}$, up to $2 \mathrm{p}$ for $\mathrm{S}$ and up to $5 \mathrm{p}$ for W. NEB calculations were performed on the reactive (10-10) edge-plane termination of $\mathrm{WS}_{2}$, with a single diphenyl oxide molecule dissociatively adsorbed at the surface. For simplicity, the edge surface was represented using only one $\mathrm{WS}_{2}$ trilayer. This was built as a nanoribbon, with periodicity in only one crystallographic direction. Five intermediate geometries (images) were built to represent the dissociative adsorption path of diphenyl oxide at the surface.

\section{Results and discussion}

\subsection{D-WS 2 characterization}

Transmission electron microscopy images were recorded to assess whether the exfoliation process generated 2D $\mathrm{WS}_{2}$ nanostructures. Figure 1 shows representative images recorded for the samples extracted from the nanofluids prepared. The presence of nanosheets is observed in nanofluids \#1, \#2 and \#3 (Figures 1a-c), but the exfoliation process was not highly efficient because the electro-transparency of the nanostructures generated was low. 
Nanosheets were observed but nanostructures that appeared not to be exfoliated were also apparent. Figure 1d shows TEM images obtained for nanofluid \#4, which was prepared using the $\mathrm{CTAB}$ concentration that best fits the ratio between the surface tension components for the solid and the base fluid. In this case, we can observe a better exfoliation of the bulk $\mathrm{WS}_{2}$ and nanosheets with high electro-transparency.

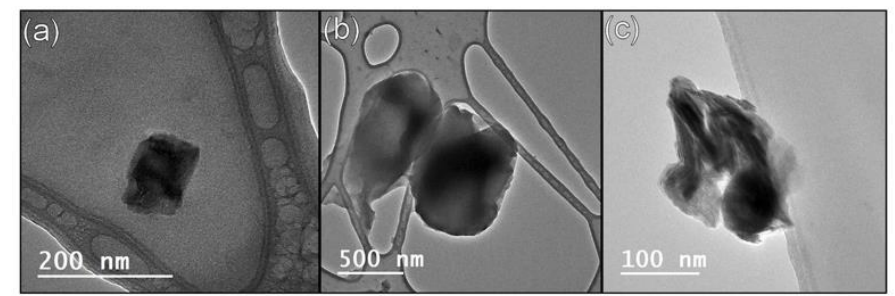

(d)
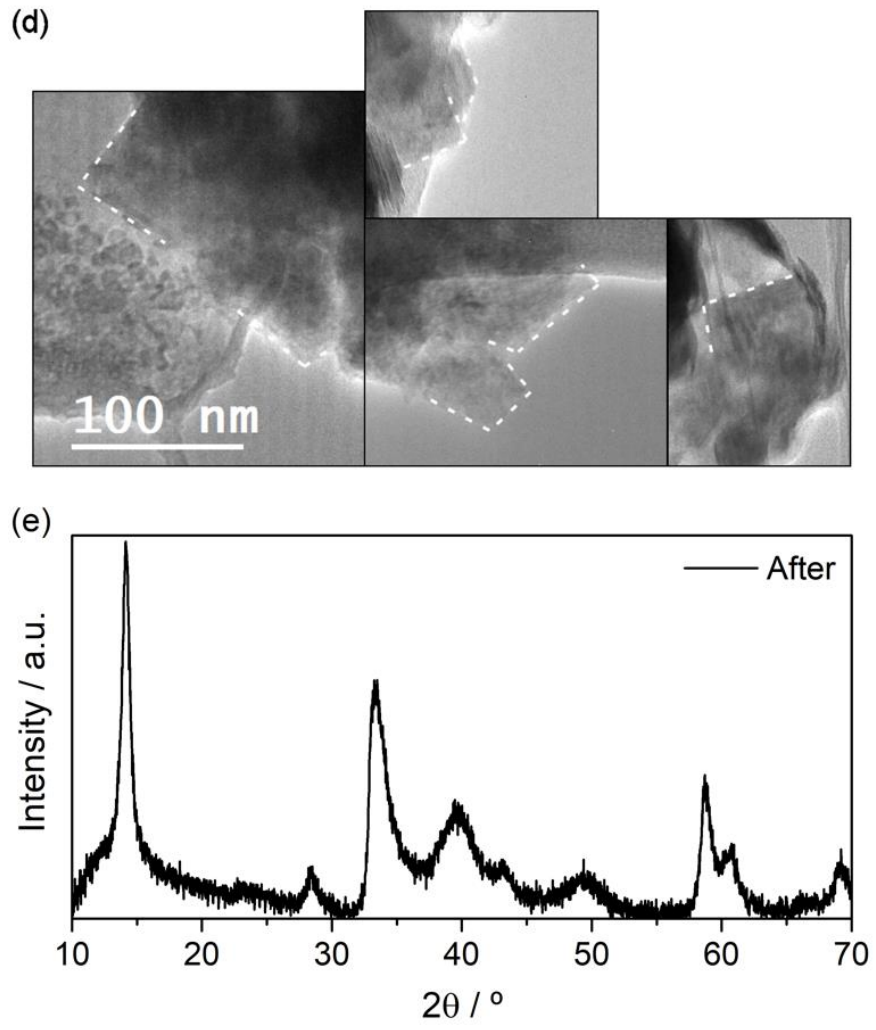

Figure 1. TEM images for nanofluids \#1 (a), \#2 (b), \#3 (c), and \#4 (d); and XRD pattern recorded from the solid extracted from nanofluid \#4 after the LPE process (e). 
XRD was used to analyze the $\mathrm{WS}_{2}$ obtained after the LPE process. The solid was extracted from nanofluid \#4, which shows a better efficiency in the exfoliation process, and the XRD pattern was recorded. It is shown in Figure 1e. The diffraction peaks at $2 \theta$ values of $14.2^{\circ}$, $28.5^{\circ}, 33.0^{\circ}, 33.7^{\circ}, 39.6^{\circ}, 42.9^{\circ}$ and $49.4^{\circ}$ are assigned to the diffraction planes (002), (004), (100), (101), (103), (006) and (105) of $\mathrm{WS}_{2}$ with a hexagonal structure (P63/mmc space group) according to the reference JCPDS 08-0237. The strong diffuse background and weak (002) peak indicate that $\mathrm{WS}_{2}$ layers were packed in a highly disordered manner and with low stacking. ${ }^{42-43}$

\subsection{Nanofluid stability}

Stability is a key factor in the performance of nanofluids because the load and size of heat carriers, namely the nanostructures in the nanofluids, are vital factors in heat conduction processes. Consequently, changes in the amount and size of heat carriers should be registered to determine the stability of nanofluids. The amount of $2 \mathrm{D}-\mathrm{WS}_{2}$ in the nanofluids prepared was evaluated from extinction coefficient. Figure S1 in the Supporting Information shows the spectra registered for the nanofluids after preparation. The presence of $\mathrm{WS}_{2}$ nanosheets is confirmed by the observation of the characteristic peak at about $629 \mathrm{~nm} .{ }^{44}$ Also, this value of wavelength is chosen for checking the evolution of the sedimentation process. These spectra show that no chemical differences were observed in the nanomaterial exfoliated in each case. Figure 2 shows the extinction coefficient values recorded each day at $\lambda=629 \mathrm{~nm}$ for the nanofluids. A decrease in the extinction coefficient was observed for nanofluids \#1 and \#2, while no significant decrease was found for nanofluids \#3 and \#4. This is probably due to the centrifugation process after exfoliation, which leads to a practically stable load 
being obtained. However, the absolute extinction coefficient values are the most important result. The values obtained for nanofluids \#1 and \#2 were very low, which means the load of nanomaterial in suspension after the exfoliation process is poor. Furthermore, neither of these nanofluids was stable at the beginning, probably due to incomplete exfoliation. Nanofluid \#3 presented higher extinction coefficient values and is clearly more stable than nanofluids \#1 and \#2. However, the highest values found were those obtained for nanofluid \#4, meaning that the highest load of nanomaterial in suspension was found for this nanofluid. Therefore, the exfoliation process was clearly more efficient for nanofluid \#4, which is consistent with the results obtained from TEM. Moreover, no changes were found in the extinction coefficient for this nanofluid, so it is stable over the time and the most promising nanofluid prepared in this study due to the high load of $2 \mathrm{D}-\mathrm{WS}_{2}$ in suspension.

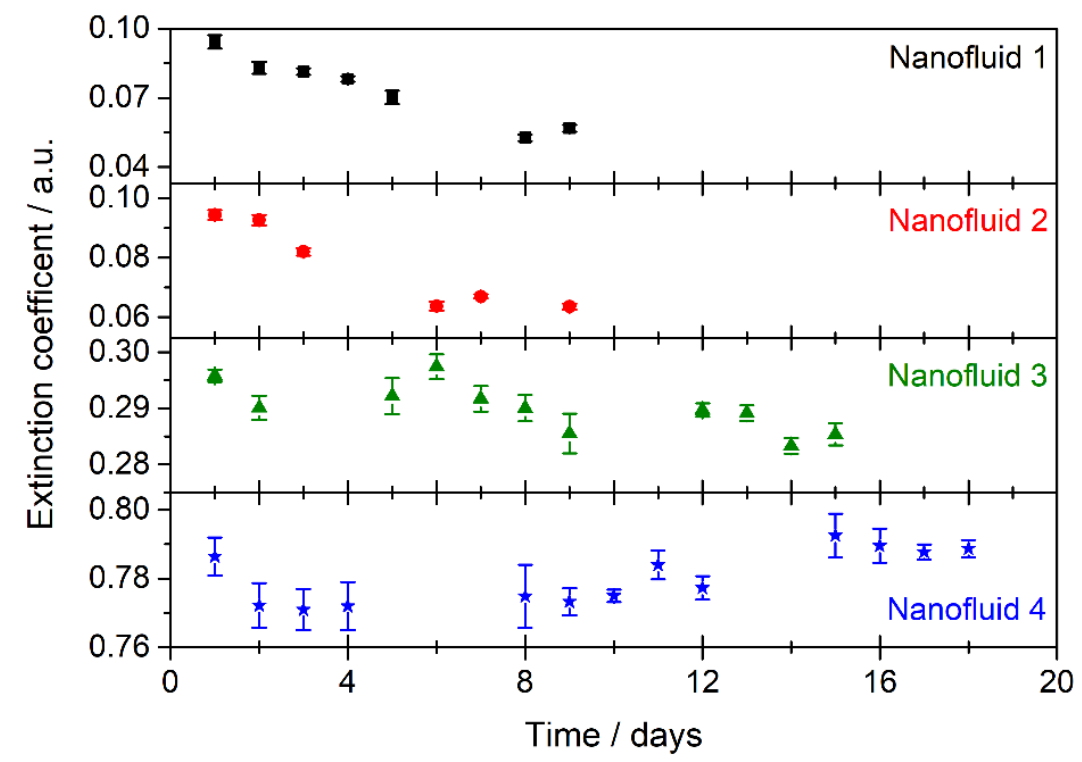

Figure 2. Extinction coefficient values at $\lambda=629 \mathrm{~nm}$ for the nanofluids prepared.

Analyzing the size of the particles in the colloidal suspension makes it possible to understand the agglomeration process taking place in the nanofluids. The average size of the heat carriers 
in terms of hydrodynamic diameter is shown in Figure 3. Nanofluids \#1 and \#2 are on average larger than $250 \mathrm{~nm}$ and show clearly particle sizes increasing with time. This is coherent with the values of extinction coefficient. The average particle size obtained for nanofluid \#3 is lower than for nanofluids \#1 and \#2 (lower than $250 \mathrm{~nm}$ ). Also, nanofluid \#3 seems to be in constant change, and the particles are seen to increase in size over time, which suggests poor stability for this nanofluid. Finally, the average size for nanofluid \#4 remained practically constant, at about $200 \mathrm{~nm}$, after more than two weeks. These results agree with those obtained from UV-Vis spectroscopy, and confirm that \#4 is the most stable of the four prepared nanofluids.

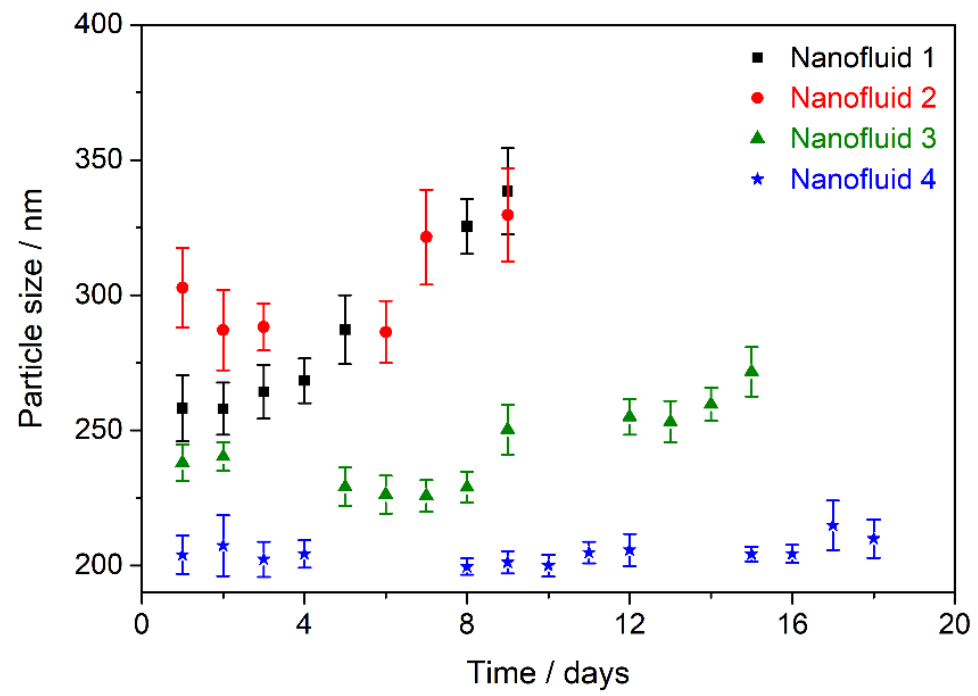

Figure 3. Average particle size obtained by DLS for the nanofluids prepared.

\subsection{Nanofluid performance}

Several thermophysical properties of the nanofluids were also analyzed in this study, to determine the nanofluid efficiency. Such properties are also involved in the heat transfer coefficient, $h$, as evidenced in the literature. ${ }^{45}$ Therefore, density, surface tension, dynamic 
viscosity, isobaric specific heat and thermal conductivity were characterized in the present study.

Numerous studies reported that heat transfer fluids are more efficient when their density increases, because of an increase in the load of nanoparticles. ${ }^{46}$ The density values measured at $298 \mathrm{~K}$ for each nanofluid are available in Table 3. Density values increase slightly for nanofluids, the highest increase of $0.45 \%$ corresponding to the nanofluid \#4, which also showed the highest extinction coefficient values due to the higher load of nanomaterial in suspension. The volume fraction was calculated according to $\phi=\left(\rho_{\mathrm{nf}}-\rho_{\mathrm{bf}}\right) /\left(\rho_{\mathrm{nm}}-\rho_{\mathrm{bf}}\right)$, where the subscripts "nf", "bf" and "nm" refer to the nanofluid, base fluid, and nanomaterial, respectively. The density of $2 \mathrm{D}-\mathrm{WS}_{2}$ is $7500 \mathrm{~kg} \mathrm{~m}^{-3} \cdot{ }^{47}$ Again, the volume fraction was highest for nanofluid \#4.

Table 3. Values of density, the increase in density and the volume fraction.

\begin{tabular}{cccc}
\hline Nanofluid & $\begin{array}{c}\rho \\
/ \mathrm{kg} \mathrm{m}^{-3}\end{array}$ & $\begin{array}{c}\left(\boldsymbol{\rho}_{\mathbf{n f}}-\boldsymbol{\rho}_{\mathbf{b f}}\right) / \boldsymbol{\rho}_{\text {bf }} \\
/ \%\end{array}$ & $\begin{array}{c}\phi \\
/ \text { vol.\% }\end{array}$ \\
\hline Base & $1056.0 \pm 0.9$ & -- & -- \\
fluid & & & \\
$\# \mathbf{1}$ & $1056.6 \pm 1.2$ & 0.06 & 0.009 \\
$\# \mathbf{2}$ & $1056.5 \pm 1.0$ & 0.05 & 0.008 \\
$\mathbf{\# 3}$ & $1057.9 \pm 1.8$ & 0.18 & 0.029 \\
$\mathbf{\# 4}$ & $1060.8 \pm 1.4$ & 0.45 & 0.075 \\
\hline
\end{tabular}

The stability analysis and density measurements lead to the conclusion that nanofluid \#4 is the most promising nanofluid. Nanofluids \#1 and \#2 show a very low load of nanomaterial, and nanofluid \#3 shows poor stability as discussed previously. Therefore nanofluid \#4 is the most promising, which may be rationalized by considering that it presents the highest load 
of nanomaterial in suspension and it is also highly stable. Therefore, this nanofluid was characterized for its rheological and thermal properties.

We now discuss the surface tension of the fluid, because of the major role this thermophysical property has in applications and processes involving heat transfer. ${ }^{48}$ The surface tension of the original HTF, the base fluid (HTF + surfactant), and nanofluid \#4 are plotted against temperature in Figure 4. A good agreement is obtained between the measured surface tension of the fluid and available manufacturer data in the range $20-40^{\circ} \mathrm{C}$ with an average deviation of $1.21 \%$. Figure 4 also shows that the surface tension of the base fluid and of nanofluid \#4 are very close to that of the pure HTF at all temperatures.

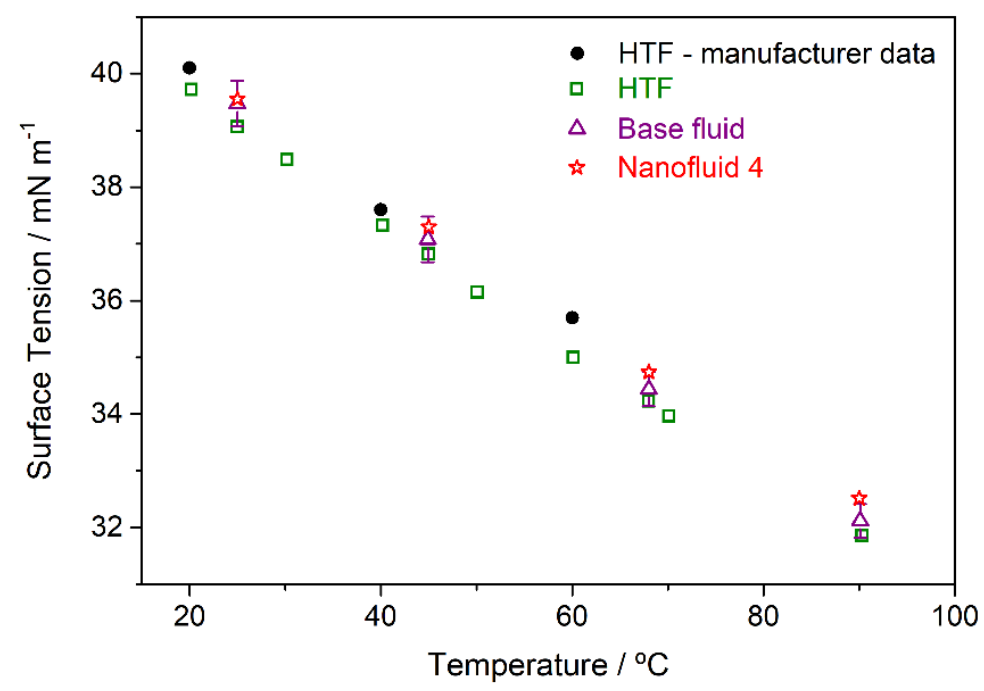

Figure 4. Surface tension of the HTF, the base fluid and nanofluid \#4.

Shear flow curves of the HTF, the base fluid and nanofluid \#4 are reported in Figure 5a. All the fluids behave in a Newtonian manner, that is for the shear rate values the viscosity is constant. Comparison of viscosity values are also reported in Figure 5b, evidencing the decrease in viscosity with temperature and showing that the viscosity of the HTF is not 
modified by the presence of surfactant and nanoparticles. The result is important because it means that the introduction of $\mathrm{WS}_{2}$ nanosheets does not modify the viscosity of the base fluid. Consequently, it will not induce any significant increase in pumping power, pressure drop or friction factor under application conditions, as demonstrated below.
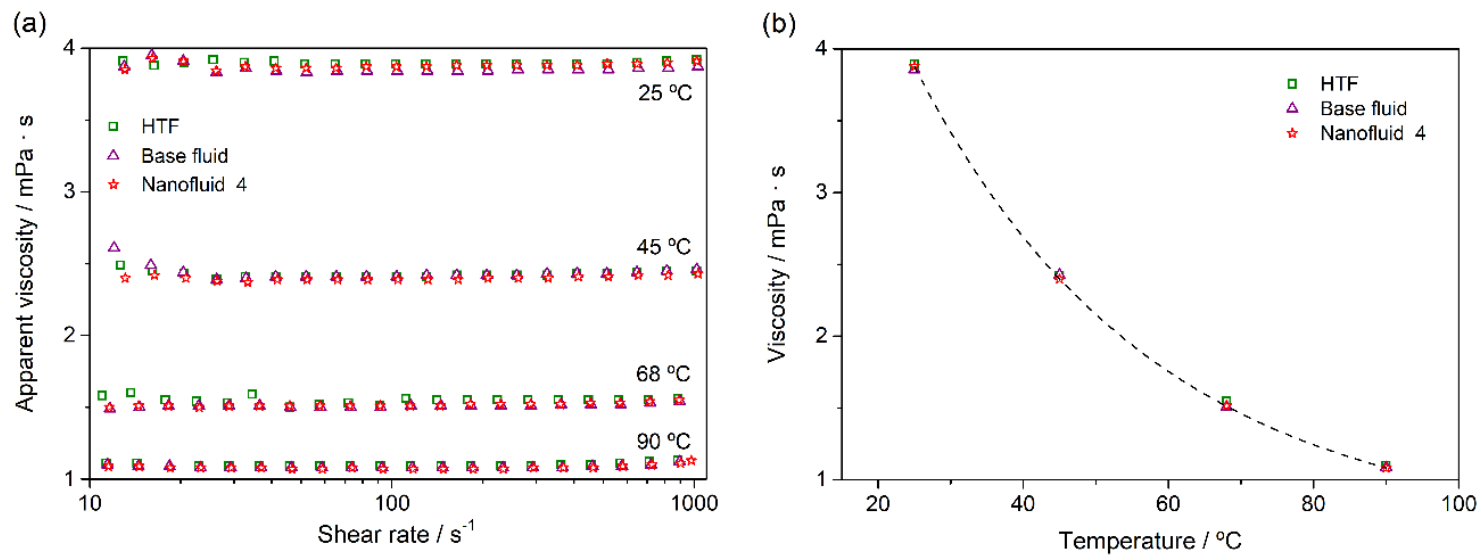

Figure 5. (a) Shear flow curves of the HTF, base fluid and nanofluid \#4 at different temperatures; (b) Viscosity of the HTF, base fluid and nanofluid \#4 against temperature.

Isobaric specific heat is a key property in heat transport because it determines the energy storage capacity of the fluids. The isobaric specific heat values obtained for the base fluid and nanofluid \#4 are shown in Figure 6a. The changes in isobaric specific heat between the HTF and the base fluid were found to be negligible, and therefore the values for the HTF are not shown for clarity of the figure. The values for the base fluid and for the nanofluid show a typical trend: the higher the temperature, the higher the isobaric specific heat. The isobaric specific heat for nanofluids is expected to decrease with respect to the base fluid because the isobaric specific heat of fluids is usually higher than that of solids, although some experimental results have shown the opposite behaviour. ${ }^{4,}{ }^{49}$ In our case, $C_{\mathrm{P}}$ decreased by about $1.6 \%$ with respect to the base fluid, but this variation is of the same order as the uncertainty of the measurements. 

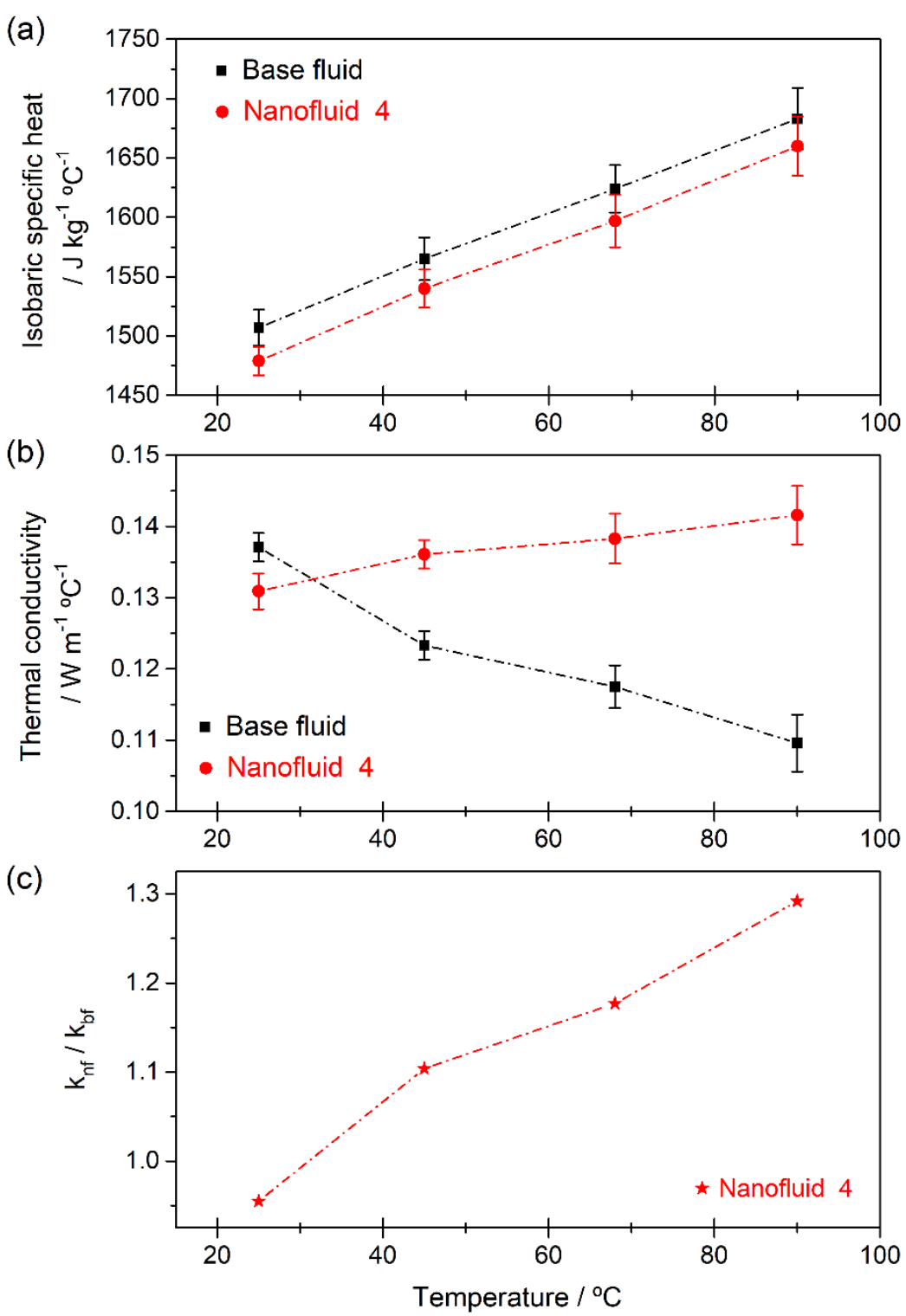

Figure 6. Temperature variation of (a) the isobaric specific heat, and (b) the thermal conductivity of the base fluid and the nanofluid \#4; (c) the ratio of the thermal conductivity values for the nanofluid \#4 and the base fluid. Dash lines joining the points are only a guide to the eye.

Figure $6 \mathrm{~b}$ shows the thermal conductivity values obtained for nanofluid \#4 and for the base fluid versus temperature. The changes in thermal conductivity between the HTF and the base fluid were found to be negligible; therefore, the values for the HTF are not shown in the 
figure for the sake of clarity. The thermal conductivity values for the nanofluid increased with temperature, which means they followed the opposite trend to the base fluid. This means that the heat conduction mechanism in the nanofluids may be different to that of the base fluid. This different trend with temperature leads to an important enhancement of thermal conductivity at temperatures get close to $100{ }^{\circ} \mathrm{C}$. Figure $6 \mathrm{c}$ shows the ratio of the thermal conductivity values for nanofluid \#4 and the base fluid ( $\left.k_{\mathrm{nf}} / k_{\mathrm{bf}}\right)$, which gives the thermal conductivity enhancement for nanofluid \#4. The highest increase was about $30 \%$ at $90^{\circ} \mathrm{C}$. The large thermal conductivity enhancement is a promising feature for solar thermal applications.

The performance of the nanofluids in CSP applications can be characterized by the useful energy production $\left(Q_{\mathrm{u}}\right)$, which can be calculated as $Q_{\mathrm{u}}=U_{\mathrm{r}} A_{\mathrm{ri}} \Delta T$, where $A_{\mathrm{ri}}$ is the internal surface of the receiver and $\Delta T$ is the temperature difference between the receiver and the fluid. $U_{\mathrm{r}}$ is a factor which considers the typical enhancement of the heat transfer coefficient, $h$, and also the heat that can be moved from the fluid, typically defined from $\left(\rho C_{\mathrm{P}}\right) .{ }^{12}$ When the values of e $\left(\rho C_{\mathrm{P}}\right)$ are higher, the heat moved increases, and this leads to an enhancement in the thermal efficiency. $U_{\mathrm{r}}$ is defined as:

$$
U_{\mathrm{r}}=\left(\frac{1}{h}+\frac{A_{r}}{2\left(\rho C_{\mathrm{P}}\right) V}\right)^{-1}
$$

being $V$ the flow rate. Higher values of $U_{\mathrm{r}}$ imply lower temperature values in the solar receiver, if $Q_{u}$ is assumed to be constant. This means the higher the $U_{\mathrm{r}}$ values, the lower the temperature in the receiver and the lower the thermal losses. If thermal losses are decreased, the solar collector will be more efficient. Thus, the thermal efficiency will be higher when $U_{\mathrm{r}}$ 
values are high. A comparison of $U_{\mathrm{r}}$ values for the base fluid and nanofluid gives the performance enhancement of the nanofluid with respect to the typical HTF used in CSP plants. Details of the calculations of $U_{\mathrm{r}}$ are shown in the Supporting Information. Figure 7 shows the values of $U_{\mathrm{r}}$ for the base fluid and for the nanofluid \#4 at several flow rates between 100 and $300 \mathrm{~L} \mathrm{~min}^{-1}$. In all cases, an increase in $U_{\mathrm{r}}$ is observed for the nanofluid. In the figure, the ratio between the $U_{\mathrm{r}}$ values for the nanofluid respect to the base fluid is included in the right side. We can observe an enhancement of up to $22 \%$, which is promising for the use of this kind of nanofluid in CSP plants.
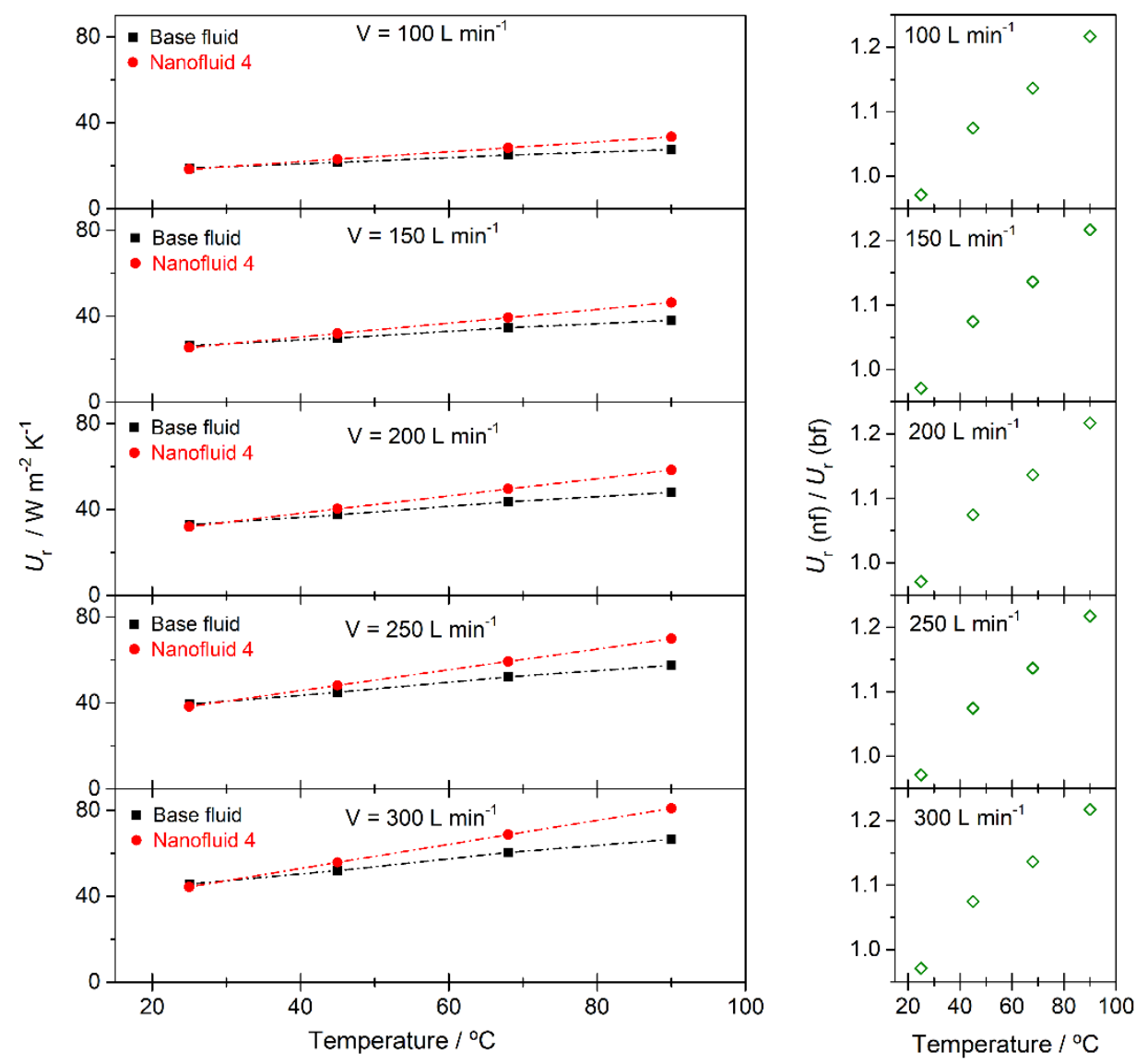

Figure 7. $U_{\mathrm{r}}$ values and the ratio between the values of the nanofluid with respect to the base fluid at several flow rates. Dash lines joining the points are only a guide to the eye. 
In addition, the friction factor $(f)$ can also be evaluated, as a performance indicator of the nanofluid in comparison to the base fluid, from the thermophysical properties experimentally determined. This is done using the following equation: ${ }^{50}$

$$
f=0.25\left[\log \left(\frac{150.39}{R e^{0.98865}}-\frac{152.66}{R e}\right)\right]^{-2}
$$

where $R e=\rho V_{\mathrm{av}} D / \mu$ is the Reynolds number. $V_{\mathrm{av}}$ and $D$ are the average fluid velocity in the inner pipe, and the inner pipe diameter, respectively. Such an equation is valid for $R e=3000-10^{8}$, turbulent flow and smooth pipes that generally compose CSP collector. An inner tube diameter $D$ of $0.066 \mathrm{~m}$ was considered ${ }^{12}$ and flow rates were varied between 100 $300 \mathrm{~L} / \mathrm{min}^{12}$ as done for the evaluation of $U_{\mathrm{r}}$. It is observed in Figure 8 that, due to the slight change of both density and viscosity of the nanofluid in comparison to base fluid, that $R e$ number and the friction factor of the nanofluid are not significantly modified compared to the base fluid, which is a positive feature for CSP applications. As expected, the Re number increases and the friction factor decreases when the flow rate increases or the temperature decreases. 


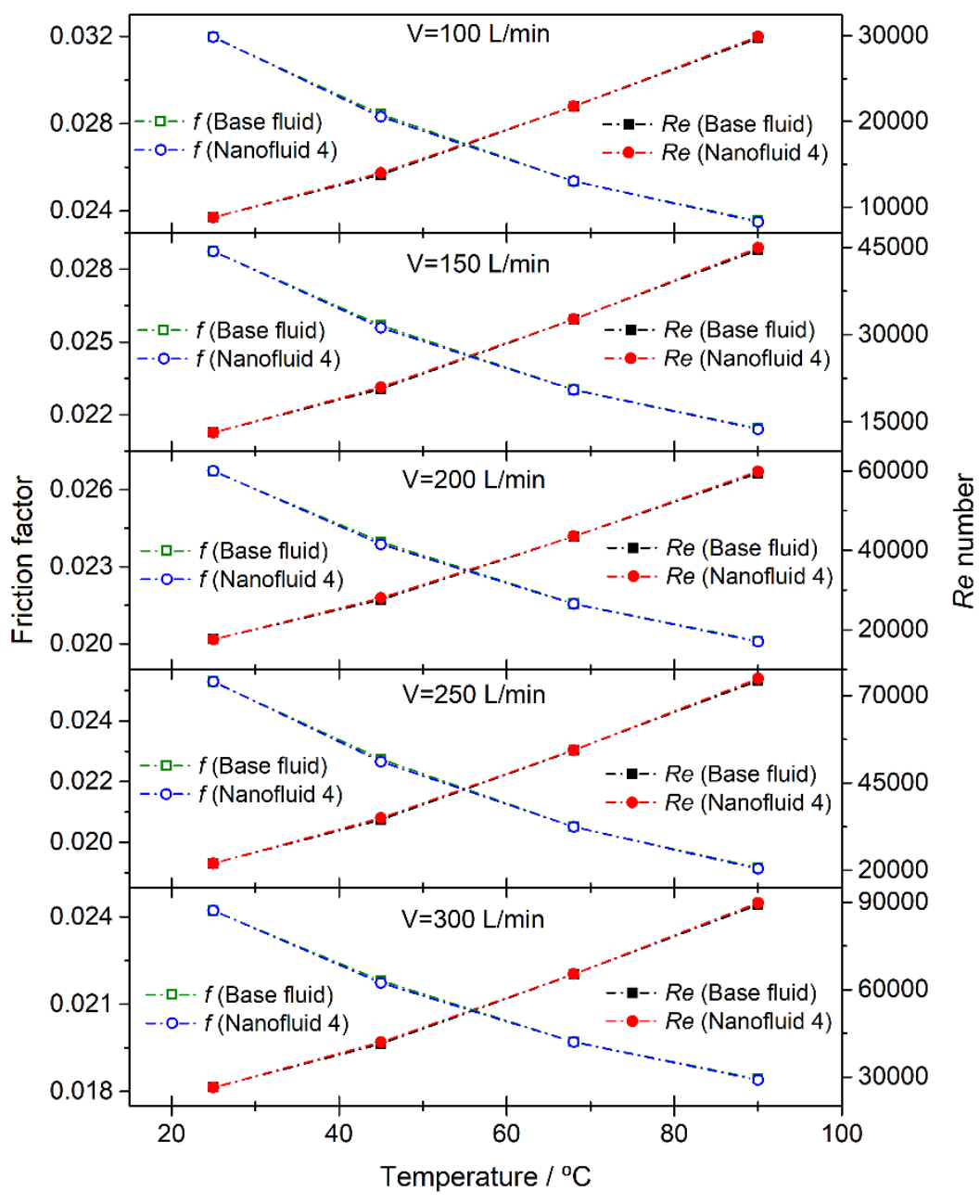

Figure 8. Influence of temperature and flow rate in the friction factor and $R e$ number for the base fluid and the nanofluid \#4. Dash lines joining the points are only a guide to the eye.

The performance of this nanofluid seems to be promising for CSP applications, which is a high temperature application (at about $380^{\circ} \mathrm{C}$ in parabolic through collector technology). At these high temperatures, some undesirable processes may occur. Thus, nanofluid was tested in thermal cycles, reaching $573 \mathrm{~K}$ without stirring. The nanofluid was heated for $5 \mathrm{~h}$, and the evaporation of the fluid was controlled. Figure 9 a shows the results obtained for the 
extinction coefficient at $\lambda=629 \mathrm{~nm}$ before and after each cycle. After the first cycle, a slight increase of the extinction coefficient was observed. After three cycles, the changes in extinction coefficient are negligible, therefore the nanofluid reaches stability. In the inset of Figure 9a, the UV-vis spectra registered at the beginning and at the end of these tests are shown. We cannot observe significant changes in the spectra, suggesting that no chemical changes occur in the nanofluid after thermal cycles. Also, Figure 9b shows the values of the mean particle size. The values of particle size are stable for all cycles, confirming that the nanofluid remains stable after thermal cycles.
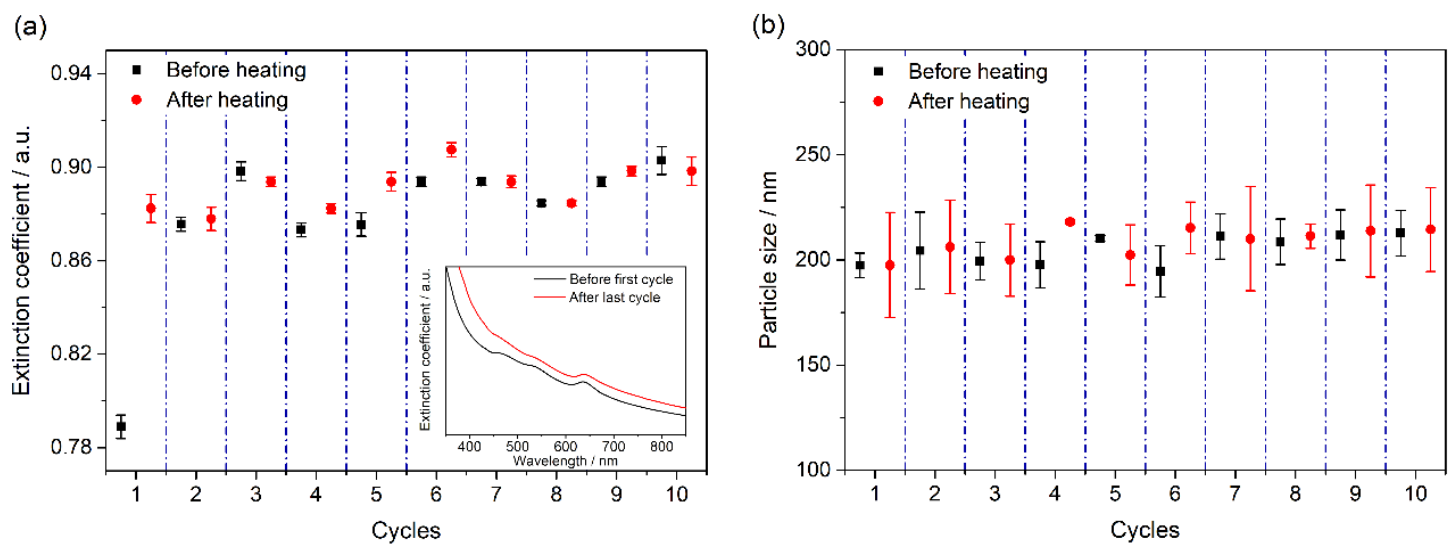

Figure 9. Extinction coefficient values obtained at $\lambda=629 \mathrm{~nm}$ (a), and particle size values (b) for the nanofluid \#4 before and after thermal cycles.

\subsection{Base fluid-WS 2 reactivity}

In order to gain insights into the behavior of the experimental system from a molecular level viewpoint, classical and ab-initio molecular dynamics simulations were performed. 
As a preliminary analysis, we used classic molecular dynamics to study how the surfactant and base fluid molecules are placed around the $\mathrm{WS}_{2}$ slab. For this, we performed a spatial distribution function (SDF) analysis of the system up to $12.0 \AA$ A . A detailed analysis of the radial distribution function (RDF) to support this discussion is included in the Supporting Information. Figure 10 shows the SDF of the system and its associated structure. We observe six blue lobes corresponding to $\mathrm{N}$ atoms placed in a first layer around the $\mathrm{WS}_{2}$ slab belonging to six molecules of CTAB. Also, Figure 10 shows two red lobes corresponding to two $\mathrm{O}$ atoms from two diphenyl oxide molecules oriented toward the $\mathrm{W}$ from the edge from the $\mathrm{WS}_{2}$ slab. Finally, it can be appreciated the presence of soft-grey color lobes from three biphenyl molecules on the two faces of the slab. It is clear that diphenyl oxide molecules present a strong tendency to interact with the $\mathrm{W}$ atoms from the edge of the slab, which agrees with the well-defined peak from the RDF W-O pairs (see Figure S2 in the Supporting Information). Moreover, the chain of the six surfactant molecules may impede more diphenyl oxide and biphenyl molecules getting closer to the slab. The results of classical molecular dynamic simulation reveal the oxygen atoms from diphenyl oxide molecules are oriented toward $\mathrm{W}$ atoms of the $\mathrm{WS}_{2}$, mainly on the edge of the slab, which justifies the interest to explore the reactivity of the interaction between diphenyl oxide and biphenyl molecules and the $\mathrm{WS}_{2}$ by ab initio molecular dynamics, which will be discussed below. 

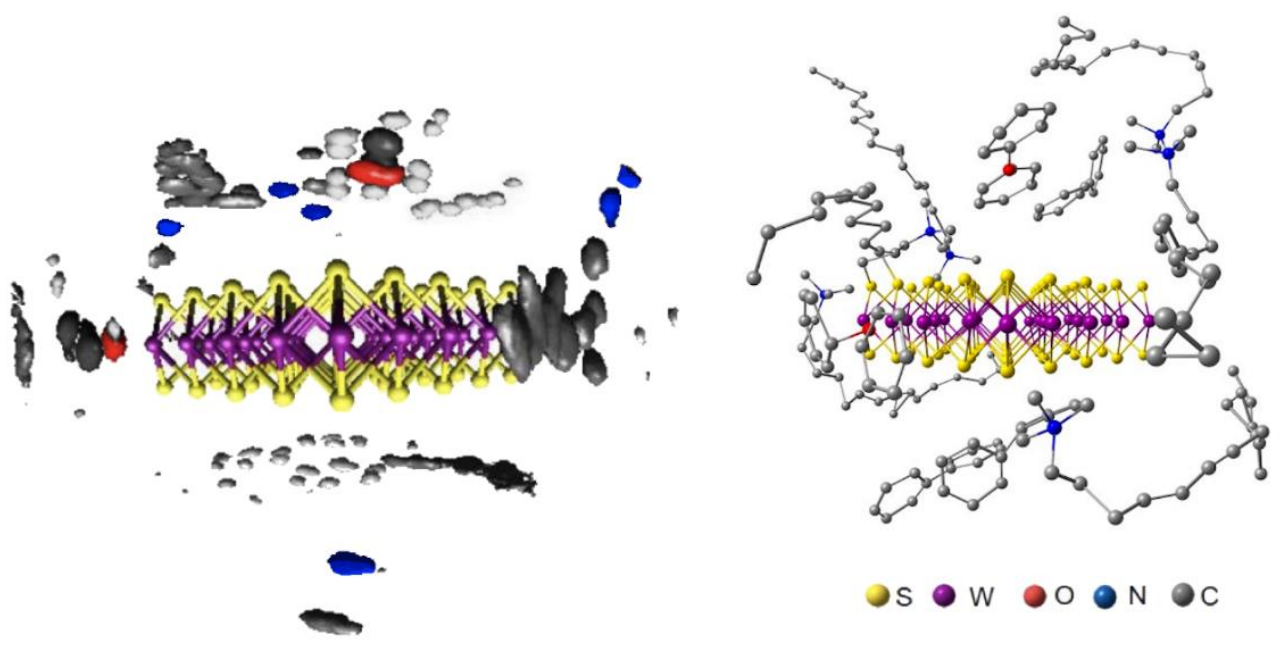

Figure 10. SDFs of the $\mathrm{WS}_{2}$ nanofluid (left side) and a representation of the structure around the $\mathrm{WS}_{2}$ slab (right side). The red-colored spatial distribution is assigned to the $\mathrm{O}$ atoms of diphenyl oxide molecules. The blue spatial distribution corresponds to the $\mathrm{N}$ atoms of the CTAB. The SDF for $\mathrm{C}$ of diphenyl oxide and biphenyl appears in soft-grey and for $\mathrm{C}$ atoms of CTAB in dark-grey.

AIMD simulations indeed reveal strong interactions between diphenyl oxide and the Wterminated $\mathrm{WS}_{2}$ (10-10) edge, which leads to a rapid dissociative adsorption of the diphenyl oxide at that edge. Such reactivity was observed to occur within the simulation time at both $300 \mathrm{~K}$ and $653 \mathrm{~K}$, suggesting a low kinetic barrier to the dissociative adsorption process. The formation of the $\mathrm{O}-\mathrm{W}$ bond was observed after $c a .2$ ps of simulation. Figure 11 shows snapshots of the AIMD simulations before and after the reaction between diphenyl oxide and the particle edge takes place. 

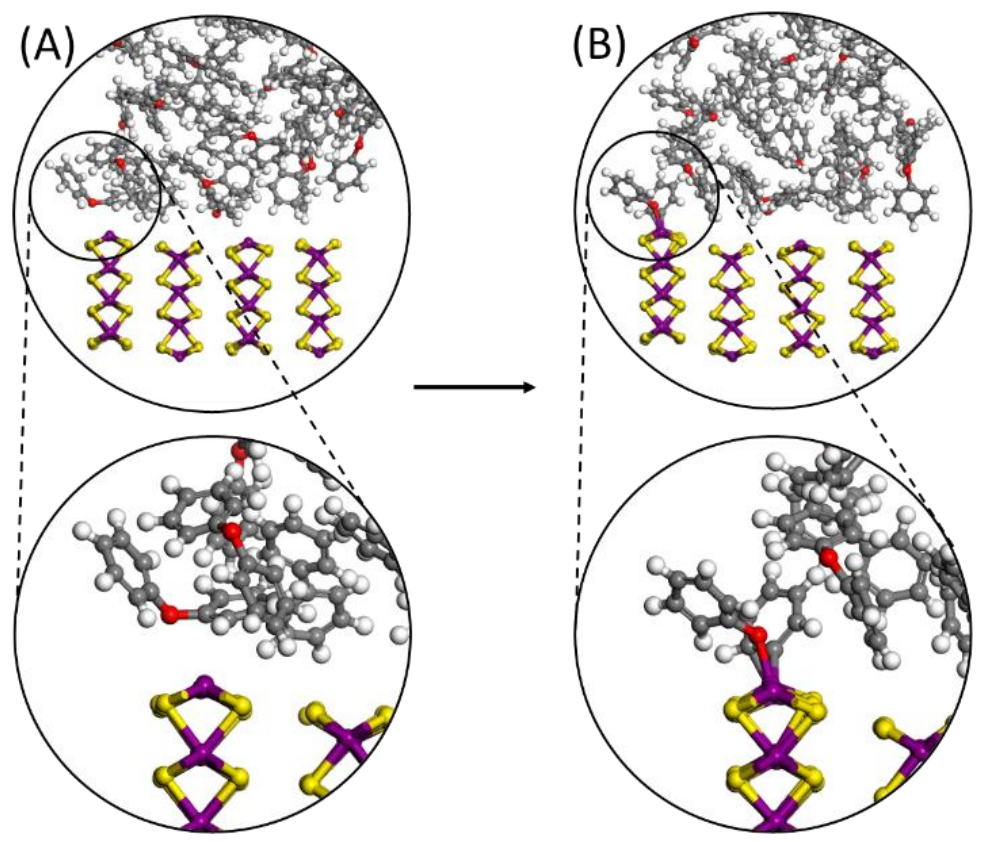

Figure 11. Two snapshots of AIMD simulation performed at $653 \mathrm{~K}$. The snapshot on the left shows the state of the system at point (A), $1.6 \mathrm{ps}$, and the snapshot on right shows the state of the system at point (B), $2.4 \mathrm{ps}$.

To quantify the transition barrier for the dissociative adsorption of diphenyl oxide, we performed nudged elastic band calculations. Figure 12 shows that there is indeed a very small energy barrier between the image zero (molecule away from the edge) and image 2 (molecule adsorbed with formation of an $\mathrm{O}-\mathrm{W}$ bond). The formation of an additional $(\mathrm{C}-\mathrm{W})$ bond precedes the breaking of the molecule, again with a small barrier of $\sim 0.2 \mathrm{eV}$. The final state is the one seen in the AIMD simulations, where both fragments are bonded to the surface, resulting in one $\mathrm{O}-\mathrm{W}$ bond and two $\mathrm{C}-\mathrm{W}$ bonds in total. The dissociative adsorption of diphenyl oxide on the $\mathrm{W}$-terminated edge is a highly exothermic process, with an energy release of $\sim 4 \mathrm{eV}$. Therefore, there is a huge driving force, and negligible kinetic barrier for this process to occur at the interface between $\mathrm{WS}_{2}$ nanoparticles and the organic fluid. 


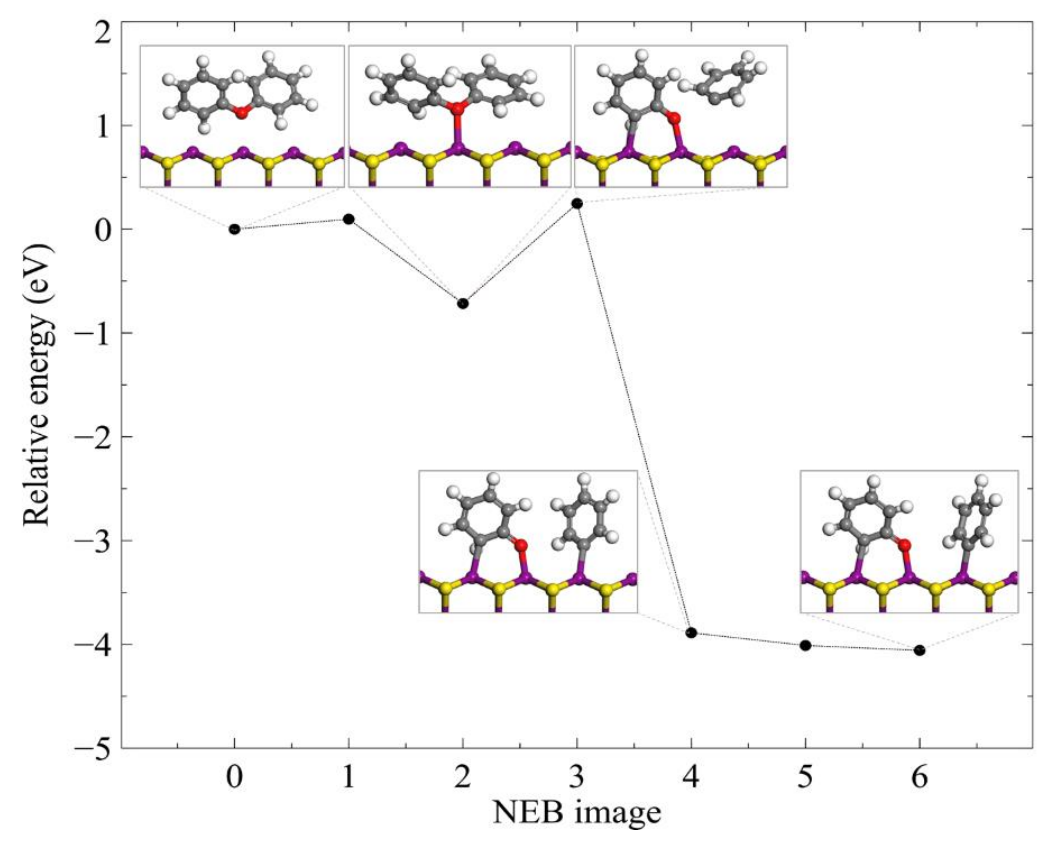

Figure 12. Results of simulations performed within the NEB method with relative energies obtained using VASP code. All energies given relative to the fist image (0), the diphenyl oxide represented as part of the 'bulk' solvent layer. Visual representation included at points of high significance.

We do not observe any reactivity in the simulations of the interface between the basal plane and the organic fluid, which can be expected from the well-known stability of that termination. Our simulations therefore suggest that the edge of the nanosheets will become decorated with fragments of diphenyl oxide almost immediately after contact with the solvent, whereas the basal planes will remain unreactive. However, further simulations would be needed to understand the possible reactivity of the basal plane, as it might occur at time scales not accessible to our current simulations. Clearly, the 'decoration' described here could have significant impact on the rheological and transport properties of the nanosheets, and this will be the subject of future theoretical and experimental research. 
To confirm the dissociative adsorption analyzed by means of AIMD from an experimental point of view, XPS measurements of the solid extracted from the nanofluid were performed. The survey spectrum (see Figure S2 in Supporting Information) shows the presence of W and $\mathrm{S}$ from $\mathrm{WS}_{2}$, but also of $\mathrm{C}$ and $\mathrm{O}$. The signals of these elements were also recorded. Figure 13a shows the signal for $\mathrm{S} 2 \mathrm{p}$. The contribution for $\mathrm{S} 2 \mathrm{p}_{3 / 2}$ was found at a binding energy (BE) of $162.5 \mathrm{eV}$, which is typical for $\mathrm{WS}_{2}{ }^{51-52}$. Furthermore, a clear splitting of the spin-orbit component doublet in the S $2 \mathrm{p}$ region is observed, showing a separation of about $1.2 \mathrm{eV}$. Figure $13 \mathrm{~b}$ shows the signal for $\mathrm{W} 4 \mathrm{f}$. This signal is complex: a spin-orbit component doublet at $\mathrm{BE}$ of 34.4 and $32.3 \mathrm{eV}$ corresponds to the $4 \mathrm{f}_{5 / 2}$ and $4 \mathrm{f}_{7 / 2}$ signals for $\mathrm{W}$ in $\mathrm{WS}_{2}{ }^{51}$,

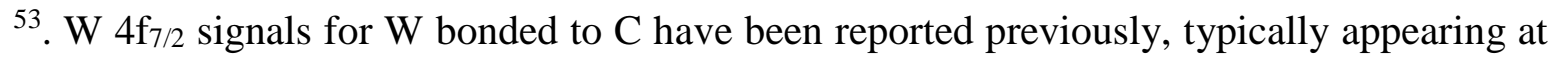
$31.8 \mathrm{eV}$. Therefore, the $\mathrm{W} 4 \mathrm{f}_{7 / 2}$ signal has been deconvoluted, and two contributions were found, as the inset of Figure 13b shows. A contribution at a BE of $31.8 \mathrm{eV}$ (highlighted as Peak 2 in the figure) was found and assigned to the W-C bond ${ }^{51}$, which can be produced due to the dissociative adsorption of biphenyl and diphenyl oxide molecules at the edges of $\mathrm{WS}_{2}$ nanosheets. This is coherent with the AIMD results shown previously. The spectrum for $\mathrm{W}$ 4f shows another doublet, generated by the splitting of the spin-orbit component of this signal. This doublet appears at BEs of 37.8 and $35.6 \mathrm{eV}$, and the peaks are assigned to $4 \mathrm{f}_{5 / 2}$ and $4 \mathrm{f}_{7 / 2}$ contributions for $\mathrm{W}$ in $\mathrm{W}(\mathrm{VI})$ oxides. ${ }^{51}$ This signal may be due to the adsorption of species on the surface, but it can also be generated by the formation of $\mathrm{W}-\mathrm{O}$ bonds when diphenyl oxide molecules are adsorbed dissociatively on $\mathrm{WS}_{2}$ nanosheets, as is shown in the AIMD results above. Figure $13 \mathrm{c}$ shows the signal for $\mathrm{C} 1 \mathrm{~s}$, and also the deconvolution of the signal. The typical peak at about $284.8 \mathrm{eV}$ (named Peak 1) is observed and assigned to adventitious carbon. Another two peaks were also found centered at 285.2 and $286.7 \mathrm{eV}$. These peaks can be assigned to $\mathrm{C}$ in phenyl rings. The peak at the lower $\mathrm{BE}$ is typically 
assigned to the $\mathrm{C}$ of the benzene rings, ${ }^{51}$ while the peak centered at the higher $\mathrm{BE}$ is assigned to the $\mathrm{C}$ belonging to benzene rings but with $\mathrm{O}$ atoms substituting $\mathrm{H}$ atoms, that is, phenol groups. ${ }^{51}$ Again, this result confirms the results obtained from AIMD calculations, namely, that diphenyl oxide molecules are dissociatively adsorbed and both fragments are bonded to the surface, resulting in $\mathrm{O}-\mathrm{W}$ and $\mathrm{C}-\mathrm{W}$ bonds. Finally, Figure $13 \mathrm{~d}$ shows the signal for $\mathrm{O} 1 \mathrm{~s}$. The signal shows a shoulder at a lower BE, which means that there are two contributions to this signal. The deconvolution of the signal is shown and two contributions were found at BEs of $532.6 \mathrm{eV}$ and $531.1 \mathrm{eV}$. The peak at the higher BE is usually assigned to adsorbed species, which can appear during the manipulation of the sample. The signal at the lower BE corresponds to the $\mathrm{O}$ atoms bonded to $\mathrm{W}$, but this signal appears slightly shifted with respect to the typical signal for $\mathrm{WO}_{3}$, which usually is found at a BE of $530.5 \mathrm{eV} .{ }^{51}$ This shift may be due to the presence of $\mathrm{W}-\mathrm{O}-\mathrm{C}$ (belonging to benzene rings) because $\mathrm{O}$ bonding to benzene rings usually appears at a higher $\mathrm{BE}$ than the $\mathrm{O}$ of the lattice from oxide compounds. Therefore, the XPS results support the prediction of dissociative adsorption the AIMD calculations, and of the 'decoration' of $\mathrm{WS}_{2}$ edges. 
(a)

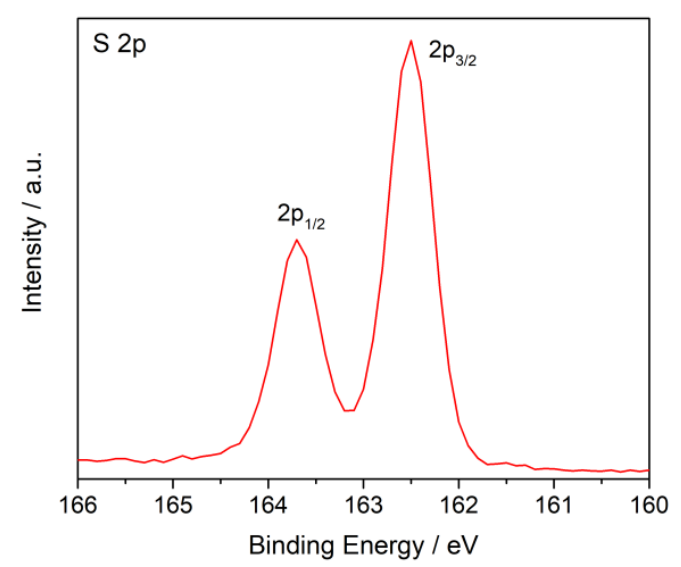

(c)

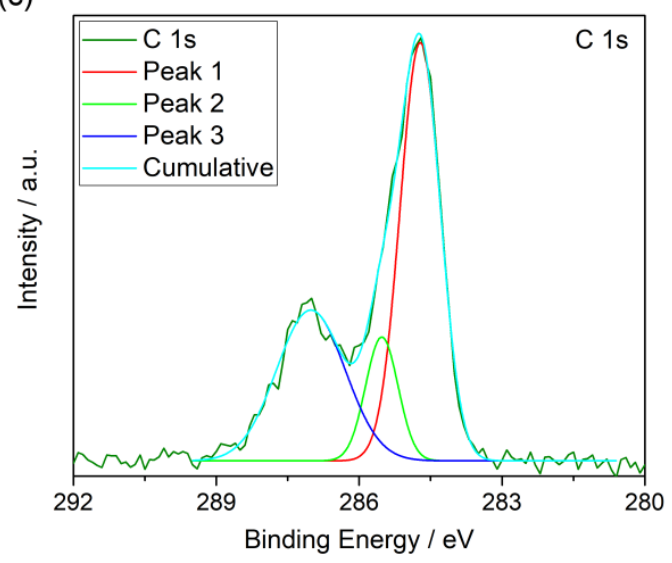

(b)

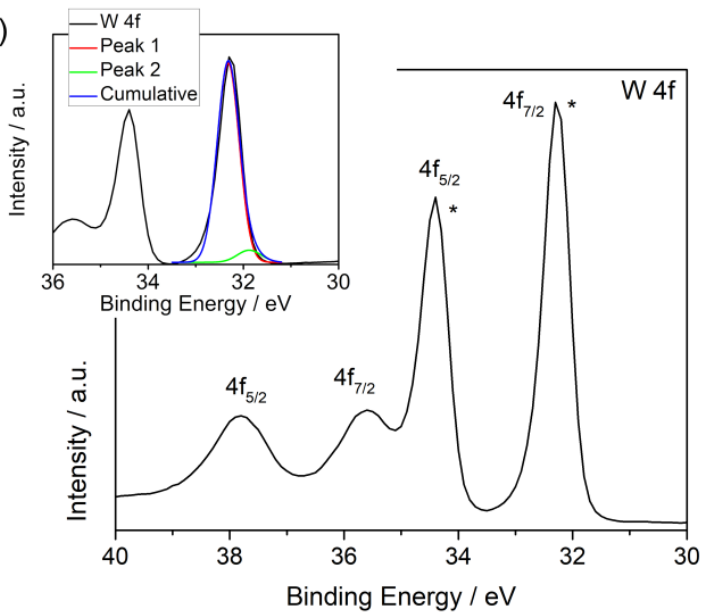

(d)

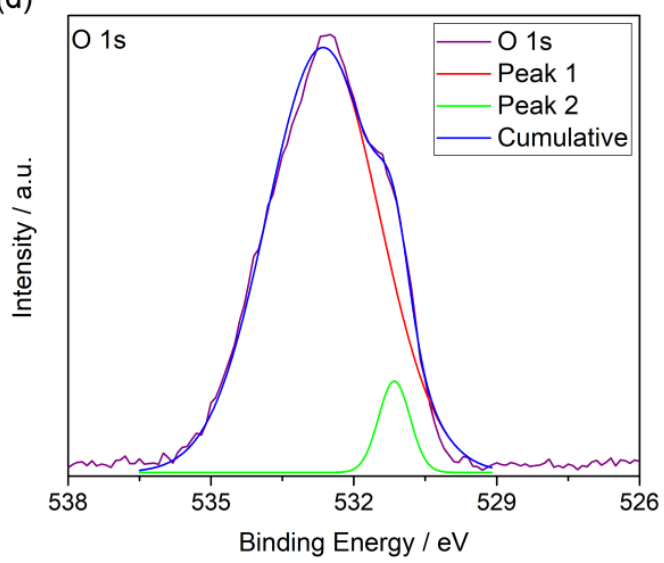

Figure 13. X-ray photoelectron spectra of (a) S 2p; (b) W 4f; (c) C 1s; and (d) O 1s obtained for the solid extracted from the nanofluid.

\section{Conclusions}

We have presented a comprehensive study of nanofluids based on $2 \mathrm{D}-\mathrm{WS}_{2}$ and have demonstrated their remarkable thermophysical properties for applications as heat transfer fluid in CSP plants. We achieved highly stable nanofluids using the liquid phase exfoliation method, as evidenced by extinction coefficient and particle size measurements. We found that the surface tension of the nanofluid did not change significantly with respect to the typical HTF used in CSP plants. From rheological measurements, we could conclude that the nanofluid behaves in Newtonian manner, and the introduction of $\mathrm{WS}_{2}$ nanosheets did not 
modify significantly the viscosity of the typical HTF used in CSP plants. Consequently, this will not induce any significant increase in pumping power, pressure drop or friction factor under real conditions. In addition, the thermal conductivity of the nanofluid was improved by up to $30 \%$ with respect to the HTF, which is promising for solar thermal applications. We observed an enhancement of up to $22 \%$ in the parameter $U_{\mathrm{r}}$ characterizing the thermal efficiency of the nanofluid in the solar collector, thus confirming that this kind of nanofluid could be very useful in CSP plants. Also, the Reynolds number and the friction factor of the nanofluid were not significantly modified compared to HTF, which is also reassuring for practical applications. Finally, thermal heating/cooling cycles were performed. We observed the nanofluid was stable in these cycles, which is also imperative for application in CSP plants.

Molecular level simulations have given us very useful insights about the structure and behavior of these $\mathrm{WS}_{2}$-based nanofluids. AIMD simulations revealed a rapid dissociative adsorption of diphenyl oxide molecules at the W-terminated $\mathrm{WS}_{2}(10-10)$ edge, occurring with a very low kinetic barrier, and a very negative adsorption energy. The dissociation fragments will remain adsorbed, decorating the edge and forming new W-O and W-C bonds, as a large energy would be required for desorption. XPS measurements confirmed the dissociative adsorption, providing clear evidence of the formation of permanent $\mathrm{W}-\mathrm{O}$ and $\mathrm{W}-$ $\mathrm{C}$ bonds in the nanofluid. The decoration of the $\mathrm{WS}_{2}$ edge could have significant impact on the rheological and transport properties of the nanofluids, and might explain some of the appealing features reported here for this kind of system, although the link between the two observations can only be speculated at the moment. This is a topic that calls for further theoretical and experimental investigation. 


\section{Acknowledgements}

We thank the Ministerio de Ciencia, Innovación y Universidades of the Spanish Government for funding under Grant No. RTI2018-096393-B-I00, and for the financial support related to measurements of thermal properties, which were carried out using devices acquired under Grant No. UNCA15-CE-2945. We also thank Andalusian Government for funding under Grant No. sol-201800107510-tra.

PE acknowledges the European Union through the European Regional Development Fund (ERDF), the Ministry of Higher Education and Research, the French region of Brittany and Rennes Métropole for the financial support of surface tension device.

This work made use of the UK national supercomputer facility ARCHER, via RGC's membership of the UK HPC Materials Chemistry Consortium, which is funded by EPSRC (EP/L000202).

Molecular Dynamics calculations were made through CICA - Centro Informático Científico de Andalucía (Spain).

\section{Supporting Information}

Calculations of the ratio of the surface tension components. UV-vis spectra registered for the nanofluids prepared. Nanofluid performance. Base fluid-surfactant-WS $\mathrm{W}_{2}$ interactions. XPS survey spectrum for $\mathrm{WS}_{2}$ exfoliated.

\section{Authors contributions}

P.M.-M. contributed to the preparation and characterization of nanofluids, and writing the article; S.D.M. contributed to the theoretical calculations of the kinetic barriers; E.I.M. contributed to the classical molecular dynamics calculations; P.E. contributed to the rheological and surface tension measurements, discussion of the results, and writing the article; R.A. contributed to the characterization of the nanofluid; A.S.C. contributed to the classical molecular dynamics calculations, and writing the article; R.G.-C. contributed to the AIMD and the kinetic barriers calculations, discussion of the results obtained, and writing the article, J.N. contributed to the direction of the work, discussion of all the results and writing the article.

\section{Conflicts of interest}

The authors declare no competing financial interests. 


\section{References}

(1) Chen, M. J.; He, Y. R.; Zhu, J. Q.; Wen, D. S. Investigating the Collector Efficiency of Silver Nanofluids Based Direct Absorption Solar Collectors. Appl. Energy 2016, 181, 65-74, DOI: 10.1016/j.apenergy.2016.08.054.

(2) Colangelo, G.; Favale, E.; Miglietta, P.; de Risi, A.; Milanese, M.; Laforgia, D. Experimental Test of an Innovative High Concentration Nanofluid Solar Collector. Appl. Energy 2015, 154, 874-881, DOI: 10.1016/j.apenergy.2015.05.031.

(3) Mwesigye, A.; Huan, Z. J.; Meyer, J. P. Thermodynamic Optimisation of the Performance of a Parabolic Trough Receiver Using Synthetic Oil- $\mathrm{Al}_{2} \mathrm{O}_{3}$ Nanofluid. Appl. Energy 2015, 156, 398-412, DOI: 10.1016/j.apenergy.2015.07.035.

(4) Navas, J.; Sánchez-Coronilla, A.; Martín, E. I.; Teruel, M.; Gallardo, J. J.; Aguilar, T.; Gómez-Villarejo, R.; Alcántara, R.; Fernández-Lorenzo, C.; Piñero, J. C.; Martín-Calleja, J. On the Enhancement of Heat Transfer Fluid for Concentrating Solar Power Using Cu and Ni Nanofluids: An Experimental and Molecular Dynamics Study. Nano Energy 2016, 27, 213224, DOI: 10.1016/j.nanoen.2016.07.004.

(5) Nguyen, C. T.; Roy, G.; Gauthier, C.; Galanis, N. Heat Transfer Enhancement Using $\mathrm{Al}_{2} \mathrm{O}_{3}-$ Water Nanofluid for an Electronic Liquid Cooling System. Appl. Therm. Eng. 2007, 27, 1501-1506, DOI: 10.1016/j.applthermaleng.2006.09.028.

(6) Buongiorno, J.; Hu, L.-W.; Kim, S. J.; Hannink, R.; Truong, B.; Forrest, E. Nanofluids for Enhanced Economics and Safety of Nuclear Reactors: An Evaluation of the Potential Features, Issues, and Research Gaps. Nucl. Technol. 2008, 162, 80-91, DOI: 10.13182/NT08A3934.

(7) Ercole, D.; Manca, O.; Vafai, K. An Investigation of Thermal Characteristics of Eutectic Molten Salt-Based Nanofluids. Int. Commun. Heat Mass Transfer 2017, 87, 98-104, DOI: 10.1016/j.icheatmasstransfer.2017.06.022.

(8) Khanafer, K.; Vafai, K. A Review on the Applications of Nanofluids in Solar Energy Field. Renewable Energy 2018, 123, 398-406, DOI: 10.1016/j.renene.2018.01.097.

(9) Sani, E.; Papi, N.; Mercatelli, L.; Zyla, G. Graphite/Diamond Ethylene Glycol-Nanofluids for Solar Energy Applications. Renewable Energy 2018, 126, 692-698, DOI: 10.1016/j.renene.2018.03.078.

(10) Sani, E.; Vallejo, J. P.; Cabaleiro, D.; Lugo, L. Functionalized Graphene NanoplateletNanofluids for Solar Thermal Collectors. Sol. Energy Mater. Sol. Cells 2018, 185, 205-209, DOI: 10.1016/j.solmat.2018.05.038.

(11) Fernández, A. G.; Gomez-Vidal, J.; Oró, E.; Kruizenga, A.; Solé, A.; Cabeza, L. F. Mainstreaming Commercial CSP Systems: A Technology Review. Renewable Energy 2019, 140, 152-176, DOI: 10.1016/j.renene.2019.03.049.

(12) Bellos, E.; Tzivanidis, C. Thermal Efficiency Enhancement of Nanofluid-Based Parabolic Trough Collectors. J. Therm. Anal. Calorim. 2019, 135 (1), 597-608, DOI: 10.1007/s10973-018-7056-7.

(13) Gomez-Villarejo, R.; Martin, E. I.; Sanchez-Coronilla, A.; Aguilar, T.; Gallardo, J. J.; Martinez-Merino, P.; Carrillo-Berdugo, I.; Alcantara, R.; Fernandez-Lorenzo, C.; Navas, J. Towards the Improvement of the Global Efficiency of Concentrating Solar Power Plants by Using Pt-Based Nanofluids: The Internal Molecular Structure Effect. Appl. Eneryg 2018, 228, 2262-2274, DOI: 10.1016/j.apenergy.2018.07.062.

(14) Yasinskiy, A.; Navas, J.; Aguilar, T.; Alcantara, R.; Gallardo, J. J.; Sanchez-Coronilla, A.; Martin, E. I.; De Los Santos, D.; Fernandez-Lorenzo, C. Dramatically Enhanced Thermal 
Properties for $\mathrm{TiO}_{2}$-Based Nanofluids for Being Used as Heat Transfer Fluids in Concentrating Solar Power Plants. Renewable Energy 2018, 119, 809-819, DOI: 10.1016/j.renene.2017.10.057.

(15) Choi, S. U. S. In Enhancing Thermal Conductivity of Fluids with Nanoparticles, 1995 ASME Int Mech Eng Congr Expo, ASME: 1995; pp 99-105.

(16) Chen, L. F.; Xie, H. Q.; Li, Y.; Yu, W. Nanofluids Containing Carbon Nanotubes Treated by Mechanochemical Reaction. Thermochim. Acta 2008, 477 (1-2), 21-24, DOI: 10.1016/j.tca.2008.08.001.

(17) Xuan, Y. M.; Li, Q. Heat Transfer Enhancement of Nanofluids. Int. J. Heat Fluid Flow 2000, 21 (1), 58-64, DOI: 10.1016/S0142-727x(99)00067-3.

(18) Fowkes, F. M. Attractive Forces at Interfaces. Ind. Eng. Chem. 1964, 56 (12), 40-\&, DOI: $10.1021 /$ ie50660a008.

(19) Owens, D. K.; Wendt, R. C. Estimation of Surface Free Energy of Polymers. J. Appl. Polym. Sci. 1969, 13 (8), 1741-1747, DOI: 10.1002/app.1969.070130815.

(20) Owens, D. K. Some Thermodynamic Aspects of Polymer Adhesion. J. Appl. Polym. Sci. 1970, 14 (7), 1725-\&, DOI: 10.1002/app.1970.070140706.

(21) Navas, J.; Martinez-Merino, P.; Sanchez-Coronilla, A.; Gallardo, J. J.; Alcantara, R.; Martin, E. I.; Pinero, J. C.; Leon, J. R.; Aguilar, T.; Toledo, J. H.; Fernandez-Lorenzo, C. $\mathrm{MoS}_{2}$ Nanosheets vs. Nanowires: Preparation and a Theoretical Study of Highly Stable and Efficient Nanofluids for Concentrating Solar Power. J. Mater. Chem. A 2018, 6 (30), 1491914929, DOI: 10.1039/c8ta03817a.

(22) Shen, J. F.; He, Y. M.; Wu, J. J.; Gao, C. T.; Keyshar, K.; Zhang, X.; Yang, Y. C.; Ye, M. X.; Vajtai, R.; Lou, J.; Ajayan, P. M. Liquid Phase Exfoliation of Two-Dimensional Materials by Directly Probing and Matching Surface Tension Components. Nano Lett. 2015, 15 (8), 5449-5454, DOI: 10.1021/acs.nanolett.5b01842.

(23) Gomez-Villarejo, R.; Aguilar, T.; Hamze, S.; Estelle, P.; Navas, J. Experimental Analysis of Water-Based Nanofluids Using Boron Nitride Nanotubes with Improved Thermal Properties. J. Mol. Liq. 2019, 277, 93-103, DOI: 10.1016/j.molliq.2018.12.093.

(24) Halelfadl, S.; Estelle, P.; Aladag, B.; Doner, N.; Mare, T. Viscosity of Carbon Nanotubes Water-Based Nanofluids: Influence of Concentration and Temperature. Int. J. Therm. Sci. 2013, 71, 111-117, DOI: 10.1016/j.ijthermalsci.2013.04.013.

(25) Schutte, W. J.; Deboer, J. L.; Jellinek, F. Crystal-Structures of Tungsten Disulfide and Diselenide. J. Solid State Chem. 1987, 70 (2), 207-209, DOI: 10.1016/0022-4596(87)900570 .

(26) Hess, P. Strength of Semiconductors, Metals, and Ceramics Evaluated by a Microscopic Cleavage Model with Morse-Type and Lennard-Jones-Type Interaction. J. Appl. Phys. 2014, 116 (5), 053515, DOI: 10.1063/1.4892016.

(27) Shah, M. S.; Tsapatsis, M.; Siepmann, J. I. Development of the Transferable Potentials for Phase Equilibria Model for Hydrogen Sulfide. J. Phys. Chem. B 2015, 119 (23), 70417052, DOI: 10.1021/acs.jpcb.5b02536.

(28) Smith, W.; Forester, T. R. DL_POLY_2.0: A General-Purpose Parallel Molecular Dynamics Simulation Package. J. Mol. Graphics 1996, 14 (3), 136-141, DOI: 10.1016/S0263-7855(96)00043-4.

(29) The CP2K Developers Group., Available at: https://www.cp2k.org/ (accessed 3 April 2019).

(30) VandeVondele, J.; Krack, M.; Mohamed, F.; Parrinello, M.; Chassaing, T.; Hutter, J. QUICKSTEP: Fast and Accurate Density Functional Calculations Using a Mixed Gaussian 
and Plane Waves Approach. Comput. Phys. Commun. 2005, 167 (2), 103-128, DOI: 10.1016/j.cpc.2004.12.014.

(31) VandeVondele, J.; Hutter, J. An Efficient Orbital Transformation Method for Electronic Structure Calculations. J. Chem. Phys. 2003, 118 (10), 4365-4369, DOI: 10.1063/1.1543154. (32) Zhang, Y. K.; Yang, W. T. Comment on "Generalized Gradient Approximation Made Simple". Phys. Rev. Lett. 1998, 80 (4), 890-890, DOI: 10.1103/PhysRevLett.80.890.

(33) Grimme, S.; Ehrlich, S.; Goerigk, L. Effect of the Damping Function in Dispersion Corrected Density Functional Theory. J. Comput. Chem. 2011, 32 (7), 1456-1465, DOI: 10.1002/jcc.21759.

(34) VandeVondele, J.; Hutter, J. Gaussian Basis Sets for Accurate Calculations on Molecular Systems in Gas and Condensed Phases. J. Chem. Phys. 2007, 127 (11), 114105, DOI: $10.1063 / 1.2770708$.

(35) Goedecker, S.; Teter, M.; Hutter, J. Separable Dual-Space Gaussian Pseudopotentials. Phys. Rev. B 1996, 54 (3), 1703-1710, DOI: 10.1103/PhysRevB.54.1703.

(36) Nose, S. A Unified Formulation of the Constant Temperature Molecular-Dynamics Methods. J. Chem. Phys. 1984, 81 (1), 511-519, DOI: 10.1063/1.447334.

(37) Kresse, G.; Furthmuller, J. Efficiency of Ab-Initio Total Energy Calculations for Metals and Semiconductors Using a Plane-Wave Basis Set. Comput. Mater. Sci. 1996, 6 (1), 15-50, DOI: 10.1016/0927-0256(96)00008-0.

(38) Kresse, G.; Furthmuller, J. Efficient Iterative Schemes for Ab Initio Total-Energy Calculations Using a Plane-Wave Basis Set. Phys. Rev. B 1996, 54 (16), 11169-11186, DOI: 10.1103/PhysRevB.54.11169.

(39) Perdew, J. P.; Burke, K.; Ernzerhof, M. Generalized Gradient Approximation Made Simple. Phys. Rev. Lett. 1996, 77 (18), 3865-3868, DOI: 10.1103/PhysRevLett.77.3865.

(40) Blochl, P. E. Projector Augmented-Wave Method. Phys. Rev. B 1994, 50 (24), 1795317979, DOI: 10.1103/PhysRevB.50.17953.

(41) Kresse, G.; Joubert, D. From Ultrasoft Pseudopotentials to the Projector AugmentedWave Method. Phys. Rev. B 1999, 59 (3), 1758-1775, DOI: 10.1103/PhysRevB.59.1758.

(42) Wu, Z. Z.; Wang, D. Z.; Sun, A. K. Surfactant-Assisted Preparation of Hexagonal Molybdenum Disulfide Nanoparticles. Mater. Let.t 2009, 63 (29), 2591-2593, DOI: 10.1016/j.matlet.2009.07.050.

(43) Zhang, X. H.; Lei, W. N.; Ye, X.; Wang, C.; Lin, B. C.; Tang, H.; Li, C. S. A Facile Synthesis and Characterization of Graphene-Like $\mathrm{WS}_{2}$ Nanosheets. Mater. Lett. 2015, 159, 399-402, DOI: 10.1016/j.matlet.2015.07.044.

(44) Coleman, J. N.; Lotya, M.; O'Neill, A.; Bergin, S. D.; King, P. J.; Khan, U.; Young, K.; Gaucher, A.; De, S.; Smith, R. J.; Shvets, I. V.; Arora, S. K.; Stanton, G.; Kim, H. Y.; Lee, K.; Kim, G. T.; Duesberg, G. S.; Hallam, T.; Boland, J. J.; Wang, J. J.; Donegan, J. F.; Grunlan, J. C.; Moriarty, G.; Shmeliov, A.; Nicholls, R. J.; Perkins, J. M.; Grieveson, E. M.; Theuwissen, K.; McComb, D. W.; Nellist, P. D.; Nicolosi, V. Two-Dimensional Nanosheets Produced by Liquid Exfoliation of Layered Materials. Science 2011, 331 (6017), 568-571, DOI: $10.1126 /$ science.1194975.

(45) Chandrasekar, M.; Suresh, S.; Senthilkumar, T. Mechanisms Proposed Through Experimental Investigations on Thermophysical Properties and Forced Convective Heat Transfer Characteristics of Various Nanofluids - A Review. Renewable Sustainable Energy Rev. 2012, 16 (6), 3917-3938, DOI: 10.1016/j.rser.2012.03.013. 
(46) Pastoriza-Gallego, M. J.; Casanova, C.; Páramo, R.; Barbés, B.; Legido, J. L.; Piñeiro, M. M. A Study on Stability and Thermophysical Properties (Density and Viscosity) of $\mathrm{Al}_{2} \mathrm{O}_{3}$ in Water Nanofluid. J. Appl. Phys. 2009, 106 (6), 064301, DOI: 10.1063/1.3187732.

(47) Eagleson, M. Concise Encyclopedia Chemistry, Walter de Gruyter: 1994; p 1201.

(48) Estelle, P.; Cabaleiro, D.; Zyla, G.; Lugo, L.; Murshed, S. M. S. Current Trends in Surface Tension and Wetting Behavior of Nanofluids. Renewable Sustainable Energy Rev 2018, 94, 931-944, DOI: 10.1016/j.rser.2018.07.006.

(49) Akyurek, E. F.; Gelis, K.; Sahin, B.; Manay, E. Experimental Analysis for Heat Transfer of Nanofluid With Wire Coil Turbulators in a Concentric Tube Heat Exchanger. Results Phys. 2018, 9, 376-389, DOI: 10.1016/j.rinp.2018.02.067.

(50) Fang, X. D.; Xu, Y.; Zhou, Z. R. New Correlations of Single-Phase Friction Factor for Turbulent Pipe Flow and Evaluation of Existing Single-Phase Friction Factor Correlations. Nucl. Eng. Des. 2011, 241 (3), 897-902, DOI: 10.1016/j.nucengdes.2010.12.019.

(51) Naumkin, A. K.-V. A. V. G., S. W.; C. J. Powell. in NIST Standard Reference Database 20, Version 4.1, Gaithersburg 2012.

(52) Chen, W. S.; Yu, X.; Zhao, Z. X.; Ji, S. C.; Feng, L. G. Hierarchical Architecture of Coupling Graphene and 2D WS 2 for High-Performance Supercapacitor. Electrochim. Acta 2019, 298, 313-320, DOI: 10.1016/j.electacta.2018.12.096.

(53) Hu, K.; Zhou, J. H.; Yi, Z. X.; Ye, C. L.; Dong, H. Y.; Yan, K. Facile Synthesis of Mesoporous $\mathrm{WS}_{2}$ for Water Oxidation. Appl. Surf. Sci. 2019, 465, 351-356, DOI: 10.1016/j.apsusc.2018.09.179. 


\section{Abstract graphic}

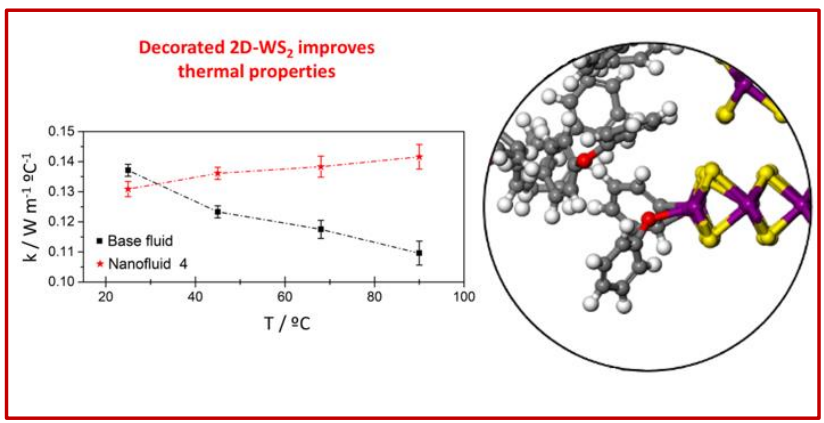

